
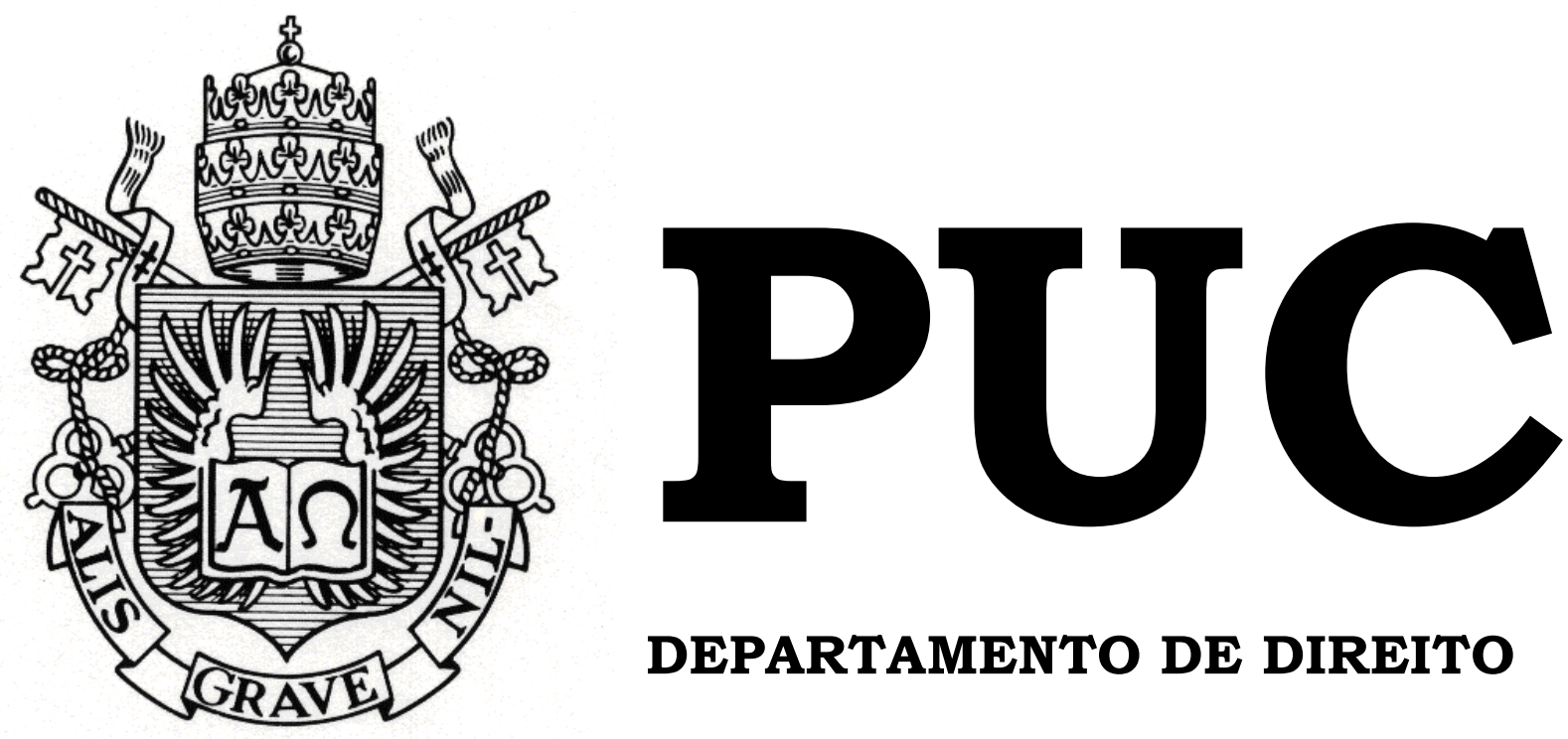

DEPARTAMENTO DE DIREITO

\title{
REGRAS DE PROTEÇÃO À FORMAÇÃO DE PREÇOS EM OFERTAS PÚBLICAS SUBSEQUENTES
}

\author{
por \\ THENARD ANTUNES FIGUEIREDO \\ ORIENTADOR: JULIAN FONSECA PEÑA \\ CHEDIAK \\ 2015.2
}

PONTIFÍCIA UNIVERSIDADE CATÓLICA DO RIO DE JANEIRO

RUA MARQUÊS DE SÃO VICENTE, 225 - CEP 22453-900

RIO DE JANEIRO - BRASIL 


\title{
REGRAS DE PROTEÇÃO À FORMAÇÃO DE PREÇOS EM OFERTAS PÚBLICAS SUBSEQUENTES
}

\author{
por \\ THENARD ANTUNES FIGUEIREDO
}

Monografia apresentada ao Departamento de Direito da Pontificia Universidade Católica do Rio de Janeiro (PUC-Rio) para a obtenção do Título de Bacharel em Direito.

Orientador: Julian Fonseca Peña Chediak 


\section{Agradecimentos}

Aos meus pais, Thenard e Sonia, que acompanharam esta odisseia com todo amor e dedicação.

À Carol, minha irmã, pelo companheirismo, ainda eu seus mil cachorros tenham me atrapalhado por toda essa monografia.

À minha avó Rosa, mais jovem do que eu.

À minha tia (e madrinha) (e viajante) Rejane.

Ao Guto e Fernanda, meus chefes no Souza Cescon, aos quais tenho como tutores e ídolos na longa carreira que espero termos juntos.

Ao professor Julian Chediak, um dos responsáveis pelo meu interesse no Direito Societário e de Mercado de Capitais.

E aos muitos amigos que poderei me reaproximar com o fim desta jornada.

Muito obrigado! 


\section{Resumo}

FIGUEIREDO, Thenard Antunes. Regras de Proteção à Formação de Preços em Ofertas Públicas Subsequentes. 57 p. Monografia (Graduação em Direito) - Pontifícia Universidade Católica do Rio de Janeiro: Rio de Janeiro, 2015.

O presente trabalho tem por objetivo a análise sistemática da Instrução CVM 530, de 23 de novembro de 2012, por meio da qual a Comissão de Valores Mobiliários passou a prever uma regra expressa destinada à proteção da formação de preços em ofertas públicas subsequentes. Para tanto, faremos uma análise essencialmente comparativa, tendo em vista a experiência acumulada pela U.S. Securities and Exchange Commission, que norteou a edição desta instrução.

\section{Palavras-chave}

Vendas a Descoberto - Short Selling - Naked Short Selling - Ofertas

Públicas Subsequentes - Seasoned Equity Offering - Follow-on Bookbuilding - Underpricing - Coordenador Líder - Underwriter Comissão de Valores Mobiliários - Instrução CVM 530/12 - Rule 105 of Regulation M - Exchange Act Rule 10b-21 - Manipulação de Mercado Instrução CVM 08/79 


\section{Sumário}

Introdução 6

Capítulo I - Ambientes de negociação de valores mobiliários ........................ 9

I.1 Mercados Regulamentados ....................................................... 9

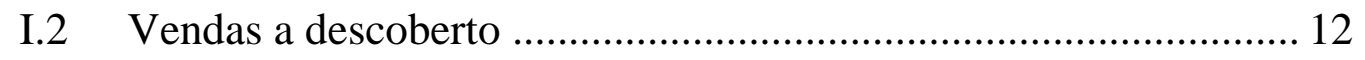

Capítulo II - Regime Jurídico de Ofertas Públicas ....................................... 18

II.1 Oferta Pública Inicial e Oferta Pública Subsequente....................... 18

II.2 Ofertas Públicas Primárias, Secundárias e Mistas ........................... 19

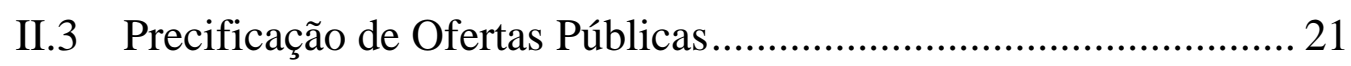

II.4 Atividade de estabilização de preços ............................................. 24

Capítulo III - Experiência norte-americana com regras de proteção a formação de preço em ofertas públicas Subsequentes …………………….... 26

III.1 Teorias econômicas acerca da necessidade de proteção ............. 26

IV.2 Enforcement da SEC............................................................ 37

Capítulo IV - Experiência brasileira com regras de proteção a formação de

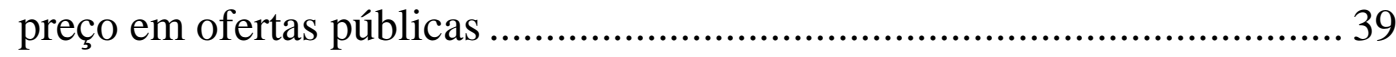

IV.1 A edição da Instrução CVM 530/2012 ………………………..... 39

IV.2 Análise do Processo Administrativo CVM RJ2013/6775 .......... 44

IV.3 A aplicabilidade da Instrução CVM 08/79 .................................. 46

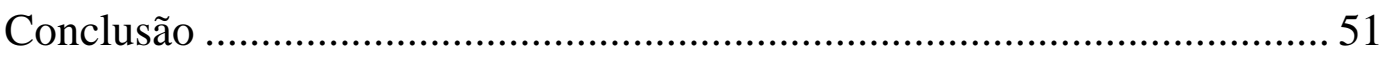

Bibliografia ................................................................................. 53 


\section{Introdução}

Com a edição da Instrução CVM 530, de 23 de novembro de 2012, (“Instrução CVM 530/12”), a Comissão de Valores Mobiliários - CVM passou a dispor de regras específicas para a proteção de preços em oferta pública subsequentes, isto é, ofertas de ações de companhias já listadas em bolsa. Assim o fez alinhando-se às melhores práticas internacionais, norteadas pela Rule 105 of Regulation M editada pela U.S. Securities and Exchange Commission - SEC ("Rule 105").

Trata-se de uma regra específica que veda a aquisição de ações, no âmbito de ofertas públicas de distribuição de ações, por investidores que tenham realizado vendas a descoberto da ação objeto na data da fixação do preço da oferta ou nos cinco pregões que a antecedem. Em outras palavras, aqueles que tenham realizado a venda de ações de que não sejam titulares, ou cuja a titularidade resulte de empréstimo ou contrato equivalente, não poderão adquirir as novas ações colocadas ao mercado por oportunidade de uma oferta pública subsequente, caso tenham realizado estas operações no período de sua precificação.

Isto porque a experiência internacional tem verificado a elevação de operações de cunho manipulativo no período de precificação de ofertas para que, intencionalmente, o preço destas novas ações seja reduzido. É parte de uma estratégia que consiste, principalmente, na tomada de ações emprestadas para a venda no período de precificação da oferta, de modo que o movimento de vendas derrube a cotação das ações, tornando-se interessante adquirir na oferta as ações necessárias para a cobertura dos empréstimos.

Como veremos, o enforcement da Rule 105, desde 2010, vem sendo uma das prioridades da SEC, dada a relevância desta norma para a proteção da capitalização das companhias abertas norte-americanas. A não-adoção de 
normas do gênero, inclusive, poderia motivar que companhias abertas brasileiras a optarem por realizar suas captações em outras jurisdições, em detrimento do desenvolvimento do mercado de capitais brasileiro.

Para a devida compreensão destas estratégias manipulativas, no Capítulo I faremos uma breve abordagem dos ambientes de negociação de valores mobiliários e da estratégia de negociação conhecida como vendas a descoberto.

No Capítulo II, compreenderemos os processos de precificação de ofertas públicas, sejam iniciais ou subsequentes, bem como o papel das instituições financeiras em ofertas de distribuição de ações.

O Capítulo III fará uma abordagem histórica das regras de proteção à formação de preços em ofertas públicas subsequentes, que remontam a 1987, com a edição, pela SEC, da Exchange Act Rule 10b-21 ("Rule 10b-21"). Sua análise será acompanhada de estudos econômicos, favoráveis e desfavoráveis às restrições impostas às estratégias baseadas em vendas a descoberto, dadas as incertezas sobre seus reais efeitos na precificação de ofertas públicas subsequentes.

Aproveitaremos para analisar o processo evolutivo da Rule 10b-21, que culminou, em 1996, com a edição da Rule 105, e na sua grande reforma, em 2008.

No Capítulo IV, faremos a análise da Instrução CVM 530/12 sob a ótica da experiência acumulada pela SEC com a Rule $10 b-21$ e a Rule 105, manifestas inspirações da CVM para a edição desta instrução.

Por fim, tendo em vista o pretenso caráter manipulativo de estratégias relacionadas às Ofertas Públicas Subsequentes, comentaremos acerca do 
possível enquadramento das condutas vedadas pela da Instrução CVM 08, de 15 de outubro de 1979, (“Instrução CVM 08/79”), em análise comparativa com a Instrução CVM 530/12. 


\section{Capítulo I - Ambientes de negociação de valores mobiliários}

\section{I.1 Mercados Regulamentados}

Nos termos do artigo $1^{\circ}$ da Instrução CVM 461, de 23 de outubro de 2007, (“Instrução CVM 461/07”), os mercados regulamentados de valores mobiliários compreendem os mercados bolsa de valores, balcão organizado e balcão não-organizado.

A Instrução 461/07 teve como motivações a ampliação da competência normativa da CVM - que a partir de 2001 passou a incluir a disciplina completa das bolsas de valores e de mercadorias e futuros - e a necessidade de modernizar as regras aplicáveis às bolsas e aos mercados de balcão organizado, preparando a regulação para as mudanças que nos últimos anos vêm acontecendo nos mercados secundários de valores mobiliários. ${ }^{1}$

Em definição de EIZIRIK:

"O mercado de balcão está segmentado em duas categorias: o organizado, no qual as operações são supervisionadas por uma instituição auto-reguladora e pela própria CVM e o mercado de balcão não organizado, no qual não há supervisão por parte de uma entidade auto-reguladora.

No mercado de balcão organizado os contatos entre as instituições intermediárias são estruturados por meio de um sistema que interliga as instituições credenciadas, processando suas ordens de compra e venda e fechando os negócios eletronicamente."

Ou seja, a distinção entre o mercado de balcão não organizado e o organizado, faz-se, essencialmente, pela sujeição à supervisão de uma

\footnotetext{
${ }^{1}$ COMISSÃO DE VALORES MOBILIÁRIOS. CVM publica Instrução 461, que disciplina os mercados regulamentados de valores mobiliários. Disponível em: $<$ http://www.cvm.gov.br/noticias/arquivos/2007/20071023-1.html > Acesso em 02 de novembro de 2015

${ }^{2}$ EIZIRIK, Nelson, et al. Mercado de Capitais: Regime Jurídico. Rio de Janeiro: Renovar, 2008, p. 238
} 
entidade auto reguladora e da CVM. Esta distinção advém do artigo 21 da

Lei 6.385 de 7 de dezembro de 1976, conforme alterada ("Lei 6.385/76"):

\begin{abstract}
“Art. 21 (...) § $5^{\circ} \mathrm{O}$ mercado de balcão organizado será administrado por entidades cujo funcionamento dependerá de autorização da Comissão de Valores Mobiliários, que expedirá normas gerais sobre:

I - condições de constituição e extinção, forma jurídica, órgãos de administração e seu preenchimento;

II - exercício do poder disciplinar pelas entidades, sobre os seus participantes ou membros, imposição de penas e casos de exclusão;

III - requisitos ou condições de admissão quanto à idoneidade, capacidade financeira e habilitação técnica dos administradores e representantes das sociedades participantes ou membros;

IV - administração das entidades, emolumentos, comissões e quaisquer outros custos cobrados pelas entidades ou seus participantes ou membros, quando for o caso."
\end{abstract}

A Instrução CVM 461/07, em seu artigo $3^{\circ}$, parágrafo $2^{\circ}$, do mesmo modo, assim dispõe:

“Art. $3^{\circ}(\ldots) \$ 2^{\circ}$ Os mercados organizados de valores mobiliários devem ser administrados por entidades administradoras autorizadas pela CVM."

E na sequência, o artigo $4^{\circ}$ da mesma Instrução CVM 461/07:

"Art. $4^{o}$ Considera-se realizada em mercado de balcão ñão organizado a negociação de valores mobiliários em que intervém, como intermediário, integrante do sistema de distribuição de que tratam os incisos I, II e III do art. 15 da Lei $n^{\circ}$ 6.385, de 1976, sem que o negócio seja realizado ou registrado em mercado organizado que atenda à definição do art. $3^{\circ}$ [da sujeição à entidade administradora autorizada pela CVM]." (grifamos)

As bolsas de valores, por sua vez, têm por característica essencial o funcionamento como sistemas centralizados e multilaterais de negociação que possibilitam o encontro e a interação de ofertas de compra e de venda de valores mobiliários. ${ }^{3}$

Ainda, nos termos do artigo 73 da Instrução CVM 461/07, as bolsas de valores devem possuir características, procedimentos e regras de negociação, previamente estabelecidos e divulgados, que permitam,

\footnotetext{
${ }^{3}$ Artigo 65, inciso I, da Instrução CVM 461/07.
} 
permanentemente: (i) a regular, adequada e eficiente formação de preços;

(ii) a pronta realização, visibilidade e registro das operações realizadas; e (iii) a disseminação pública das ofertas e negócios envolvendo ativos ali negociados, com rapidez, amplitude e detalhes suficientes à boa informação do mercado e formação de preços.

\section{Segundo SANTOS:}

"Além do local físico, as bolsas de valores sempre tiveram como critério identificador distintivo a formação competitiva de preços, daí porque seu funcionamento conta om uma série de garantias destinadas a tutelá-la: o anonimato das negociações, intermediadas sem que se conheça o investidor comitente, e portanto sem que o preço possa variar em função das circunstâncias específicas deste; a compensação e liquidação obrigatória por contraparte central que assume a posição de compradora perante os vendedores e de vendedora ante aos que querem compra-los, eliminando a necessidade de avaliação do risco de crédito do comitente e assegurando que a operação será liquidada; a divulgação em tempo real das operações realizadas, já que o valor pelo qual cada negociação é fechada passa a representar o novo preço de mercado para aquele ativo; e regras voltadas a dispensar tratamento especial a operações com valores mobiliários com características peculiares em termos de quantidade e de preço (.....)"4

Com a implementação de sistemas eletrônicos de negociação, porém, as definições de bolsa e mercado de balcão organizado se aproximaram. Isso porque, ainda segundo SANTOS, as garantias então previstas no mercado de bolsa também podem ser adotadas, à luz da Instrução CVM 461/07, pelo mercado de balcão organizado. ${ }^{5}$

Assim, cada companhia aberta, quando desejar manter ações de sua circulação negociadas no mercado, deverá optar entre o mercado de bolsa ou o mercado de balcão organizado, sendo vedada, nos termos do artigo 57, parágrafo $3^{\circ}$, da Instrução CVM 461/07, a negociação simultânea nestes dois segmentos. Será admitida, no entanto a listagem simultânea de suas ações em mais de uma bolsa de valores, ou mais de um mercado de balcão organizado.

\footnotetext{
${ }^{4}$ SANTOS, Aline de Menezes. Artigo 1 ${ }^{\circ}$. In: CODORNIZ, Gabriela; PATELLA, Laura (coord.). Comentários à Lei do Mercado de Capitais - Lei n ${ }^{0}$ 6.385/76. São Paulo: Quartier Latin, 2015, p. 35 ${ }^{5}$ Ibid. p. 35
} 
No mesmo sentido, o artigo 59 da Instrução CVM 461/07 estabelece que é vedada a negociação, fora de mercado organizado, de valores mobiliários nele admitidos, exceto nas hipóteses de a) negociações privadas; b) distribuição pública, durante o período da respectiva distribuição; c) integralização de cotas de fundos e clubes de investimento, nas hipóteses admitidas na regulamentação específica; d) evento societário que determine ou permita a substituição ou permuta do valor mobiliário por outro; e) alienação em oferta pública de aquisição; e f) outras expressamente previstas em regulamentação expedida pela CVM.

A distribuição pública, por sua vez, é tarefa característica do mercado de balcão não-organizado, sendo que o $\operatorname{artigo~} 4^{\circ}$, parágrafo único, da Instrução CVM 461/07 estabelece que:

\footnotetext{
“Art. 4". Parágrafo único. Também será considerada como de balcão não organizado a negociação de valores mobiliários em que intervém, como parte, integrante do sistema de distribuição, quando tal negociação resultar do exercício da atividade de subscrição de valores mobiliários por conta própria para revenda em mercado ou de compra de valores mobiliários em circulação para revenda por conta própria."
}

Ou seja, no âmbito de uma oferta de ações, por exemplo, a subscrição dos valores mobiliários ofertados poderá ser realizada no mercado de balcão não-organizado para, após, estes ativos serem transferidos para o sistema de negociação das bolsas de valores ou do mercado de balcão organizado.

\section{I.2 Vendas a descoberto}

Existem, essencialmente, duas modalidades de vendas a descoberto; a covered short selling (lícita e amplamente conhecida) e a naked short selling (tida como irregular em diversas jurisdições).

Seguindo a síntese de SCHAHIN para o covered short selling: 
“(...) vendas a descoberto ou short sales ocorrem com a alienação ou venda de ativos tomados em empréstimo, havendo a intenção de comprar ativos idênticos em um momento posterior para devolução ao devedor. Em outras palavras, a venda a descoberto resulta na venda de uma ação ou outro ativo que o investidor não possui no momento da emissão da ordem de venda. (...)

O tomador, portanto, baseia-se na expectativa de que será possível recomprar esta ação [vendida a descoberto] a um preço inferior ao da venda e devolvê-la ao doador do empréstimo, embolsando a diferença. Diz-se do investidor que venda a descoberto que está 'curto' ou que abriu uma posição curta no respectivo instrumento financeiro. A transação de recompra do ativo é chamada 'cobertura' da posição curta." 6

A SEC, em seu turno, define o seu conceito de venda a descoberto na Regulation SHO, 17 CFR 242.200-203, da qual destacamos as alíneas (a) e (c), com a seguinte redação:

"(a) The term short sale shall mean any sale of a security which the seller does not own or any sale which is consummated by the delivery of a security borrowed by, or for the account of, the seller.

( ...)

(b) A person shall be deemed to own securities only to the extent that he has a net long position in such securities."

No mesmo sentido, CULP e HEATON, em The Economics of Naked Short Selling:

"Short sellers operate when they believe the price of a security will fall - in essence, they sell borrowed shares today at a high price and then pay back the lender with lower-priced shares in the future."7

Ou seja, em uma venda a descoberto (covered short selling) o investidor toma ações de uma determinada companhia emprestadas para revende-las no mercado acreditando que até a data de devolução deste

\footnotetext{
${ }^{6}$ SCHAHIN, Fernanda Kalil. Vendas a Descoberto no âmbito do Empréstimo de Ações: estudo do modelo regulatório brasileiro. In: Revista de Direito Bancário e do Mercado de Capitais: São Paulo: Malheiros, n. 49, ano 13, jul/set, 2010, p.38

${ }^{7}$ CULP, Christopher L., HEATON, J.B. The Economics of Naked Short Selling: Naked shorting is little diferente from permissible shorting. Cato Institute. 2008. Disponível em: $\langle\mathrm{http}$ ://object.cato.org/sites/cato.org/files/serials/files/regulation/2008/2/v31n1-6.pdf>. Acesso em 02 de novembro de 2015. p. 7
} 
empréstimo, será possível recompra-las no mercado de bolsa a um valor inferior à primeira operação. A estratégia segue, portanto, uma avaliação deste investidor de que o ativo esteja tomado por empréstimo está sobrevalorizado.

Por serem um movimento de venda, naturalmente, ampliam a demanda pelo ativo negociado, contribuindo para a queda de suas cotações.

Como segunda modalidade de venda a descoberto - e que antecipamos ser irregular - há também o naked short selling. Nestas operações, o investidor vende uma ação a descoberto sem ter a intenção de entregar o ativo na data de liquidação, resultando numa falha de liquidação. ${ }^{8} 9$

Isso porque, no mercado à vista de bolsa de valores, as operações de compra e venda realizadas em D+0 serão liquidadas após três pregões, isto é, em D+3. É possível, portanto, que determinado investidor dê uma ordem de venda em $\mathrm{D}+0$ na expectativa que o ativo que deverá ser entregue em $\mathrm{D}+3$ seja incorporado a sua conta neste meio tempo. Quando isto não acontece, como dito, trata-se de uma falha de liquidação ${ }^{10}$.

Em comentários da CVM sobre o naked short selling:

“(...) no mercado brasileiro, não se observa esse tipo de operação, inclusive porque há mecanismos que a tornam inviável. Um deles é a realização de empréstimo automático, pela própria entidade de compensação e liquidação, na hipótese do vendedor vir a falhar na entrega das ações na data de liquidação.

\footnotetext{
${ }^{8}$ SCHAHIN, Fernanda Kalil. Op. cit., p. 38

9 "Some forms of short selling are illegal. When a seller sells stock short but has not borrowed the security or made a good faith arrangement to borrow the security, or does not reasonably believe it can borrow the security by the settlement day, the short seller is probably engaged in impermissible “naked” short selling”. CULP, Christopher L., HEATON, J.B. Op. cit., p. 7

10 Segundo os Procedimentos Operacionais da Câmara de Compensação, Liquidação e Gerenciamento de Riscos de Operações no Segmento Bovespa, e da Central Depositária de Ativos - CBLC, atual Câmara de Ações, a falta da entrega de ativos é caracterizada pela não entrega total ou parcial dos Ativos em D+3 nos horários devidos.
} 
Caso não haja ações disponiveis e a liquidação não se complete, é compulsoriamente emitida ordem de compra das ações no mercado." (grifamos)

Desse modo, no mercado brasileiro, quando ocorre uma falha de liquidação em uma operação de naked short selling, a entidade de compensação e liquidação imediatamente realiza o empréstimo dos títulos necessários para a cobertura desta primeira operação. Caso não seja possível tomar por empréstimo a quantidade de ações necessárias para a cobertura do naked short selling, será emitida uma segunda ordem compulsória, porém desta vez para compra destas ações no mercado de bolsa.

Não é, portanto, impossível que sejam realizadas, mas sim inviáveis, tendo em vistas os mecanismos compulsórios para a proteção das falhas de liquidação, e seus custo potenciais para esta modalidade de venda a descoberto.

Após a edição do Ofício Circular BM\&FBOVESPA 056/2013, estas falhas de liquidação também passaram a ser severamente multadas, conforme os percentuais apresentados no quadro abaixo:

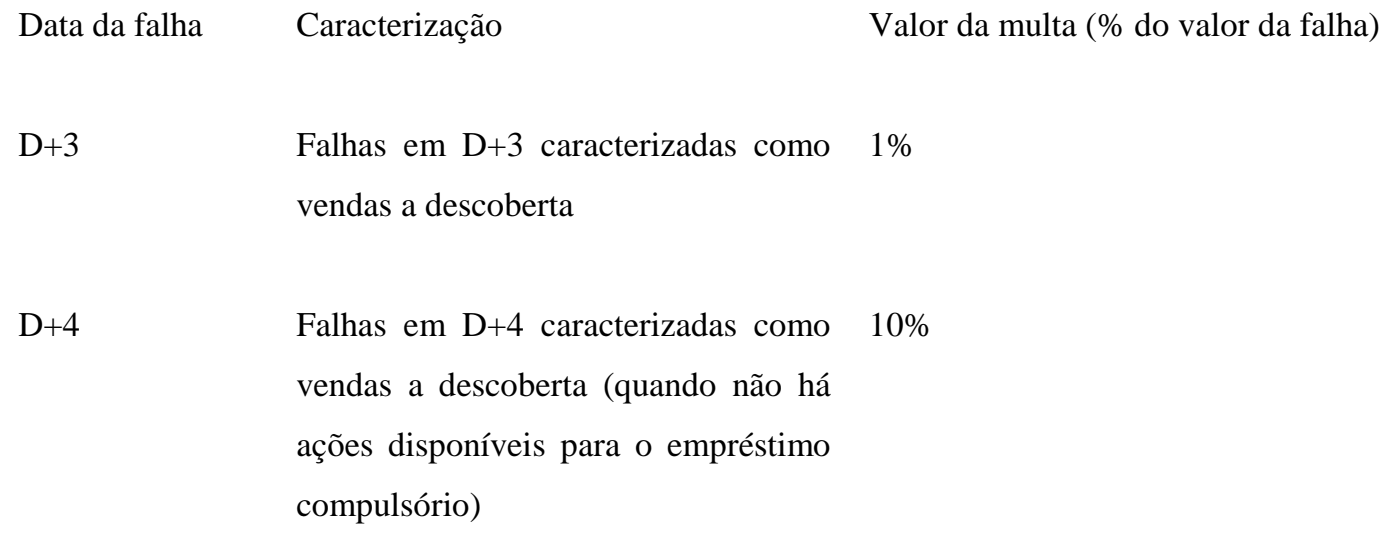

${ }^{11}$ COMISSÃO DE VALORES MOBILIÁRIOS. Comunicado IOSCO: iniciativas que impõem restrições a vendas a descoberto (Short Selling). Disponível em: $\langle$ http://www.cvm.gov.br/noticias/arquivos/2008/20081003-1.html $>$. Acesso em 08 de outubro de 2015

12 Tabela constante do Ofício Circular BM\&FBOVESPA 056/2013, disponível em: < http://www.bmfbovespa.com.br/oficiosComunicados/DownloadOficioComunicado.ashx?numDoc $=056-2013 \&$ dir $=$ Ofic \&depto=DP\&idioma=pt-br $>$. Acesso em 10 de novembro de 2015. 
Importante destacar que a venda a descoberto (covered short selling), diferentemente do naked short selling, não é tida como irregular. A Organização Internacional das Comissões de Valores - IOSCO, inclusive, reconhece que as vendas a descobertos podem trazer benefícios ao mercado de capitais, como se nota da passagem abaixo:

\begin{abstract}
"Os membros do Comitê Técnico notam que operações de short selling desempenham um papel importante e benéfico ao mercado por diversas razões, incluindo a formação mais eficiente de preços, a mitigação de bolhas no mercado, o aumento de liquidez, facilitando o uso do hedging e outras atividades de administração de riscos, e, mais importante, limitando manipulações de mercado para elevar artificialmente os preços."13
\end{abstract}

De todo modo, após a crise global de 2008, os reguladores globais passaram a restringir as vendas a descoberto de forma ainda mais rígida, de modo a preservar a saúde das instituições financeiras atuantes no mercado de capitais. Essa é a tônica do comunicado feito pela IOSCO, em outubro de 2008, tratando de restrições a vendas a descoberto.

\begin{abstract}
“(....) operações de short selling podem ser problemáticas em períodos de perda de confiança no mercado. Por exemplo, no contexto de uma crise de crédito onde instituições solventes enfrentam dificuldades de liquidez, a queda no preço de suas ações em razão de operações de short selling pode levar a uma redução ainda maior no crédito para essas instituições, podendo até mesmo levá-las à insolvência. Existem ainda circunstâncias em que as operações de short selling podem ser usadas como ferramenta para enganar o mercado. Pode-se citar, como exemplo, operações de manipulação de mercado para baixo, onde um operador vende ações de uma companhia a descoberto e divulga rumores mentirosos sobre perspectivas negativas para essa companhia. Isso prejudica emissores e investidores, assim como afeta a integridade do mercado."14
\end{abstract}

Para tanto, a IOSCO recomendou medidas como:

a) novas proibições em operações de naked short selling, através da exigência de que os operadores tomem os valores mobiliários emprestados antes de realizar as vendas a descoberto ou, alternativamente, se assegurem

${ }^{13}$ Ibid.
${ }^{14}$ Ibid. 
de que poderão tomar esses valores emprestados para atender à liquidação da operação de venda, garantindo ainda que essas limitações não impactem negativamente setores importantes do mercado, como o de empréstimo de ações;

b) exigência de que determinados investidores informem sobre as operações de short selling que executem, ou sobre as posições líquidas a descoberto que carreguem, aos reguladores, entidades de auto-regulação ou ao público em geral; e

c) aumento da supervisão das negociações para detectar short selling abusivo;

Muito embora as regras de proteção à formação de preços em ofertas públicas subsequentes tenham sua origem nos anos 80, conforme será detalhado adiante, a crise de 2008 chamou atenção à preocupação regulatória com as vendas a descoberto, ainda que paire absoluta incerteza sobre os seus benefícios e malefícios. 


\title{
Capítulo II - Regime Jurídico de Ofertas Públicas
}

\section{II.1 Oferta Pública Inicial e Oferta Pública Subsequente}

Por meio da "Oferta Pública Inicial", também conhecida pela sigla IPO (Initial Public Offering) uma determinada companhia distribui ações ou certificados de depósito de ações de sua emissão ao mercado de valores mobiliários. Comumente, porém não como regra, estas companhias optam pelo ingresso no mercado de bolsa de valores, sendo também possível, como alternativa, sua listagem no mercado de balcão organizado.

\section{Conforme EIZIRIK:}

\begin{abstract}
"Normalmente, são registradas para negociação no mercado de balcão organizado ações emitidas por companhias de menor porte e que, justamente por esta razão, teriam sua visibilidade, exposição e a própria liquidez prejudicadas por papéis emitidos por companhias de grande porte, caso fossem negociadas em bolsa de valores. Em vista disso, costuma-se dizer que o mercado de balcão organizado funciona como uma 'porta de entrada' para o ingresso de novas companhias no mercado de capitais." 15
\end{abstract}

$\mathrm{Na}$ "Oferta Pública Subsequente", por sua vez, também conhecida como follow-on ou seasoned equity offering, as ações (ou certificado de depósito de ações) então ofertadas já são negociadas no mercado secundário.

Entre os anos de 2004 e 2015, foram 112 Ofertas Públicas Subsequentes no mercado brasileiro, enquanto que, no mesmo período, foram registradas 153 Ofertas Públicas Iniciais. ${ }^{16}$

Com a recente reforma da Instrução CVM 476, de 16 de janeiro de 2009, as ofertas públicas de ações também poderão ser realizadas por meio

\footnotetext{
${ }^{15}$ EIZIRIK, Nelson. Op. cit., p. 239

16 Segundo informações disponibilizadas pela BM\&FBOVESPA. Disponível em: $<$ http://www.bmfbovespa.com.br/pt-br/mercados/download/BMFBOVESPA-Ofertas-Publicas-eIPOS.xlsx> Acesso em: 15 de novembro de 2015.
} 
de esforços restritos, modalidade de oferta exclusivamente dirigida a investidores profissionais. ${ }^{17}$

\section{II.2 Ofertas Públicas Primárias, Secundárias e Mistas}

O regime da Lei 6.404 de 15 de dezembro de 1976, conforme alterada, ("Lei 6.404/76") prevê em duas hipóteses as Ofertas Públicas Primárias de ações (subscrição pública de ações), quais sejam:

a) a constituição de companhia por subscrição pública; ${ }^{18} \mathrm{e}$

b) aumento de capital mediante a subscrição pública de ações, depois de realizados, no mínimo, 3/4 do capital social. ${ }^{19}$

A constituição de companhia por subscrição pública, evidentemente, pressupõe que esta sociedade sequer tenha ações emitidas e, portanto, será hipótese exclusiva de Oferta Pública Inicial.

No aumento de capital mediante subscrição pública de ações, em seu turno, a companhia já será constituída e terá, ao menos, 3/4 de seu capital social integralizado.

Como exemplos recentes de Ofertas Públicas Primárias, podemos mencionar as Ofertas Públicas Iniciais da Smiles S.A. (2013) e Biosev S.A. (2013), bem como as Ofertas Públicas Subsequentes da Oi S.A. (2014) e Iguatemi Empresa de Shopping Centers S.A. (2013)

\footnotetext{
${ }^{17}$ A Instrução CVM 554, de 17 de dezembro de 2015, incluiu as ações no rol de valores mobiliários autorizados a oferta por meio da modalidade de esforços restritos.

${ }^{18}$ Artigo 82 da Lei $6.404 / 76$

${ }^{19}$ Artigo 170 da Lei 6.404/76
} 
Diferentemente das Ofertas Públicas Primárias, nas “Ofertas Públicas Secundárias" não ocorre o aumento de capital da companhia emissora das ações objeto da oferta. Nesta modalidade de oferta, somente os acionistas da companhia, sejam controladores ou não, vendem as suas ações. ${ }^{20}$

Como exemplos recentes de Ofertas Públicas Secundárias, podemos mencionar as Ofertas Públicas Iniciais da Par Corretora de Seguros S.A. (2015) e CVC Brasil Operadora e Agência de Viagens S.A. (2013), bem como as Ofertas Públicas Subsequentes da EDP - Energias do Brasil S.A. (2011) e Mahle Metal Leve S.A. (2011).

A mais comum das hipóteses, porém, é a de ofertas públicas com características Primárias e Secundárias, onde o montante captado é destinado tanto à capitalização da companhia, quanto à compra de ações então pertencentes a determinados acionistas. Estas ofertas são conhecidas como "Ofertas Públicas Mistas".

Como exemplos recentes de Ofertas Públicas Mistas, podemos mencionar as Ofertas Públicas Iniciais da Ouro Fino Saúde Animal Participações S.A. (2014) e Gaec Educação S.A. (2013), bem como as Ofertas Públicas Subsequentes da Estácio Participações S.A. (2013) e Minerva S.A. (2012).

\footnotetext{
${ }^{20}$ Para a hipótese de Oferta Pública Secundária realizada por acionista não controlador, a Instrução CVM 400/03 prevê, em seu artigo 56, parágrafo $3^{\circ}$, um regime diferenciado para a declaração de veracidade das informações prestadas ao mercado.
} 


\section{II.3 Precificação de Ofertas Públicas}

Até o início dos anos 1990, predominavam duas formas de precificação nas "aberturas de capital" de companhias brasileiras; a "construção do livro de demandas" (bookbuilding) e o preço fixo. ${ }^{21}$

No início dos anos 2000, porém, com a globalização dos mercados de capitais, os países que então restringiam o procedimento de bookbuilding passaram a flexibilizar a utilização deste modelo, predominante no mercado norte-americano.

No bookbuilding, a instituição financeira designada para a coordenação da oferta ("Coordenador Líder") ${ }^{22}$, em concordância com o ofertante, define uma faixa indicativa de preços para sondagem a potenciais investidores.

Na sequência, o Coordenador Líder coleta intenções de compras de investidores institucionais diretamente ou por meio de outros membros do consórcio de intermediários de forma a, antes da oferta, traçar a curva de demanda do título ofertado. ${ }^{23}$

Conforme SAITO e PEREIRA, no Brasil, "Todos os investidores são identificados, ou seja, não existem ordens anônimas, e o book ou livro de ordens é mantido confidencialmente pelos intermediários." 24

\footnotetext{
${ }^{21}$ SAITO, Richard; PEREIRA, João André C.M. Bookbuilding e Alocação Estratégica: Evidência do Mercado de Capitais Brasileiro. Evidência do Mercado Brasileiro de Ações, Revista Brasileira de Finanças, v. 4, 2006, p. 32

${ }^{22}$ Também referido como Intermediário Líder ou Underwriter.

${ }^{23}$ SAITO, Richard; PEREIRA, João André C.M. Op. Cit., p.32

${ }^{24}$ Ibid. p.32
} 
Algumas jurisdições, porém, exigem o disclosure em tempo real da composição do bookbuilding, como ocorre na Índia, por exemplo. ${ }^{25}$

As intenções coletadas consistem na indicação de combinações preço/quantidade, faixas indicativas de preços, preços limites, step-bids (definem como o preço afetará suas demandas), ou a combinação destes métodos. $^{26}$

\section{Segundo EIZIRIK:}

"Tais procedimentos - consultas sobre a viabilidade de oferta a potenciais investidores $e$ as coletas de intenções de investimento - contribuem inequivocamente para a redução do pricing risk e do marketing risk que existem em toda oferta pública de valores mobiliários, uma vez que permitem aferir a potencial demanda existente dos investidores e compartilhar o preço e as condições de remuneração dos títulos à situação do mercado. ${ }^{27}$

Em regra, estas intenções de compra apresentadas pelos investidores institucionais não são vinculativas, sendo que a própria Instrução CVM 400, de 29 de dezembro de 2003 (“Instrução CVM 400/03"), em seu artigo 44, dispõe que a coleta de intenções de investimento poderá ser recebida com ou sem pedidos de reserva.

Porém, na prática, os potenciais investidores tendem a manter suas intenções de compra de forma a preservar o seu relacionamento com o coordenador líder da oferta.

Nesse sentido, CHEN, MORRISON e WILHELM: ${ }^{28}$

\footnotetext{
${ }^{25}$ KHURSHED, Arif, et al. Transparent Bookbuilding, certification and initial public offerings. Journal of Financial Markets. vol. 19. 2014, p. 156

26 JENKINSON, Tim; JONES, Howard. Bids Allocations in European IPO Bookbuilding. The Journal of Finance. vol. 59, no 5. 2004, p. 2312

${ }^{27}$ EIZIRIK, Nelson. Op. cit., p. 203

${ }^{28}$ CHEN, Zhaohui. et al. Another Look at Bookbuilding, Auctions, and the future of the IPO Process. Journal of Applied Corporate Finance. vol. 26. n 2. 2014, p. 21
} 
"Although these indicative bids are not legally binding, investors who do not stand by them run the risk that they will damage their relationship with the bank [Coordenador Líder] - more on this in a moment."

Evidentemente, para as Ofertas Públicas Subsequentes, as intenções manifestadas pelos investidores institucionais têm relação direta com a cotações em bolsa de valores destas ações ofertadas, ainda que este não seja o único parâmetro para a curva de demanda. Este ponto é de extrema relevância para a compreensão das Regras de Proteção à Formação de Preços em Ofertas Públicas Subsequentes, como veremos adiante.

Após a coleta destas intenções, o Coordenador Líder, discricionariamente, determina o preço praticado na oferta e a quantidade de ações que cada investidor institucional que tenha participado do bookbuilding poderá comprar.

Esta decisão, em muitos momentos, leva em consideração a estrutura acionária da companhia emissora após a oferta, sendo comum que os coordenadores evitem a aquisição de grandes blocos por um mesmo acionista. Ainda, variáveis como o tipo e tamanho de ordem, a frequência de participação dos investidores, nacionalidade e tipo institucional também influenciam na alocação das ações.

Após o bookbuilding, os investidores não-institucionais (varejo) poderão aderir à oferta no preço então definido.

Diferentemente do bookbuilding, e como o próprio nome demonstra, nas ofertas realizadas por preço fixo - quase inexistentes atualmente - o Coordenador Líder determina o preço da oferta sem que tenha sido realizada a coleta de intenções de compra. 
Também incomuns no mercado brasileiro, mas ainda presentes no mercado norte-americano, é também possível precificação de ofertas públicas por meio de leilão. Nesta modalidade, o consórcio de bancos intermediários da oferta realiza roadshows para investidores institucionais e, desde 2005, também a investidores não-institucionais. ${ }^{29}$

\section{II.4 Atividade de estabilização de preços}

Além da colocação no mercado dos valores mobiliários, o Coordenador Líder também pode desempenhar atividade fundamental para garantir a liquidez dos papeis então ofertados, conhecida como a "estabilização de preços".

Nesta atividade de estabilização, o Coordenador Líder, por um período contratualmente determinado, realiza compras e vendas dos valores mobiliários então ofertados, com a intenção de auxiliar o mercado na geração de liquidez destes ativos, bem como assegurar que a sua cotação não sofra drásticas oscilações.

Segundo a SEC:

"Although stabilization is a price-influencing activity intended to induce others to purchase the offered security, when appropriately regulated it is an effective mechanism for fostering an orderly distribution of securities and promotes the interests of shareholders, underwriters, and issuers ${ }^{\prime 30}$ (grifamos)

De modo manter o mercado informado acerca desta atividade de estabilização de preços, nos termos do artigo 23 , parágrafo $3^{\circ}$, da Instrução CVM 400/03, o contrato de estabilização de preços, quando houver, deverá ser previamente aprovado pela CVM.

\footnotetext{
${ }^{29}$ Ibid. p. 21

${ }^{30}$ U.S SECURITIES AND EXCHANGE COMMISSION. Regulation M: Release No. 34-38067. 1997. Disponível em: <https://www.sec.gov/rules/final/34-38067.txt〉. Acesso em 10 de novembro de 2015. p. 81.
} 
O principal mecanismo utilizado pelo Coordenador Líder é a colocação em excesso de ações após a oferta mediante o exercício da opção de sobre-alocação (greenshoe option) que deverá ser autorizado pelo ofertante. ${ }^{31}$ Esta opção está prevista no artigo 24 da Instrução CVM 400/03, permitindo a alocação posterior de até $15 \%$ da quantidade de valores mobiliários inicialmente ofertada.

\section{Conforme EIZIRIK:}

"Além de permitir uma captação adicional de recursos por parte da companhia, a green shoe option tem a função de preservar a estabilidade do preço dos valores mobiliários emitidos, na medida em que o underwriter pode aumentar o volume ofertado e, com isso, evitar flutuações causadas por excesso de demanda." ${ }^{32}$

No sentido contrário, quando os valores mobiliários então ofertados não encontram demanda suficiente no mercado, o Coordenador Líder recomprará estes títulos nos mercados secundários, até que, discricionariamente, atinja o preço idealizado como estável.

\footnotetext{
${ }^{31}$ PINHEIRO, Douglas Beserra; CARVALHO, Antonio Gledson. A Relevância do Processo de Estabilização no Retorno de Curto Prazo dos IPOs. 2009. Disponível em: <http://webcache.googleusercontent.com/search?q=cache:fOxzoDEm49sJ:bibliotecadigital.fgv.br/ ocs/index.php/sbe/EBE09/paper/download/983/371+\&cd=1\&hl=en\&ct=clnk\&gl=br $>$. Acesso em 10 de novembro de 2015

${ }^{32}$ EIZIRIK, Nelson, et al. Mercado de Capitais: Regime Jurídico. Rio de Janeiro: Renovar, 2011, p. 207
} 


\section{Capítulo III - Experiência norte-americana com regras de proteção a formação de preço em Ofertas Públicas Subsequentes}

\section{III.1 Teorias econômicas acerca da necessidade de proteção}

Antes de adentrarmos aos aspectos jurídicos das regras de proteção à formação de preço em Ofertas Públicas Subsequentes, será necessária uma breve passagem sobre as principais teorias econômicas desenvolvidas sobre o tema, que está longe de ser pacífico.

SMITH (1977) foi o primeiro autor a analisar o underpricing (deságio em relação ao preço praticado em mercado) em Ofertas Públicas Subsequentes, utilizando-se de uma amostra de 328 ofertas para indicar que as cotações na data da oferta apresentavam uma queda média de 0,54\%, enquanto que no pós-oferta, obtinham um retorno positivo de $0,82 \% .{ }^{33}$

Estudos posteriores, como o de BHAGAT e FROST (1986) e ECKBO e MASULIS (1992), também indicaram que as Ofertas Públicas Subsequentes vinham, sequencialmente, apresentando retornos positivos nos pregões seguintes a sua realização

Para alguns, porém, este underpricing teria uma origem manipulativa.

Em 1974 a National Association of Securities Dealers - NASD propôs à SEC a adoção de vedações à prática de vendas a descoberto em períodos anteriores à realização das Ofertas Públicas Subsequentes, entendendo que estas negociações seriam utilizadas com intuito fraudulento, garantindo

\footnotetext{
${ }^{33}$ SMITH, Clifford W. Alternative methods for raising capital: Rights versus underwritten offerings. Journal of Financial Economics. vol. 5. 1977, pp. 273-307
} 
lucros manipulativos a determinados investidores, ocasionando prejuízos a precificação de destas ofertas, na forma de underpricing.

Estas estratégias consistiriam na realização de uma venda a descoberto por determinado investidor no período de precificação da Oferta Pública Subsequente - usualmente o bookbuilding - com a intenção exclusiva de iniciar uma pressão vendedora sob as ações objeto da oferta, derrubando sua cotação e permitindo que a aquisição destes mesmos papéis no âmbito da oferta garanta um lucro no momento de cobertura das suas posições.

Segundo a NASD, estes investidores não estariam sujeitos ao risco de mercado usual de operações a descoberto na medida em que a pressão vendedora iniciada asseguraria que a transação seria coberta por preços inferiores. ${ }^{34}$

Assim, a SEC adotou a "Rule 10b-21" em 1987, que vedava que as ações adquiridas na Oferta Pública Subsequente fossem destinadas à cobertura de vendas a descoberto realizadas no período entre a data de anuncio desta oferta e a data final de precificação da oferta.

Segundo estudo elaborado por SAFIEDDINE e WILHEM $(1996)^{35}$, no período anterior à adoção da Rule 10b-21, níveis elevados de vendas a descoberto teriam sido registrados nas datas anteriores às Ofertas Públicas Subsequentes, resultando em um elevado underpricing. Após a adoção desta

\footnotetext{
34 "The NASD has argued that such short sellers are not subject to the usual market risk attendant on the covering transaction as the downward pressure of the short selling all but ensures that the transactions will be covered out of the offering at a lower price.". FINANCIAL INDUSTRY REGULATORY AUTHORITY. 88-62 SEC Adopts Rule 10b-21 Prohibiting Shorting into Secondaries. 1988. Disponível em: http://finra.complinet.com/en/display/display_main.html?rbid=2403\&element_id=899\&print=1>. Acesso em 10 de novembro de 2015.

${ }^{35}$ SAFIEDDINE, A.; WILHELM, W. An Empirical Investigation of Short-Selling Activity Prior to Seasoned Equity Offerings. The Journal of Finance. vol. 51. n 2. 1996, pp. $729-749$
} 
regra de proteção, segundo estes, o underpricing teria reduzido, naquilo que concluíram pelo sucesso da adoção desta norma. ${ }^{36}$

Há, porém, divergência quanto aos efeitos da Rule 10b-21.

GERARD e NANDA (1993), por exemplo, entendem que as vedações excessivas à realização de vendas a descoberto impostas pela Rule 10b-21 teriam, ao contrário, prejudicado a precificação das ações então ofertadas, resultando na elevação do underpricing. ${ }^{37}$

Em comentários de HENRY e KOSKI:

"Gerard and Nanda incorporate short sales and the possibility of strategic trading. In their model, manipulative trading prior to the SEO worsens the winner's problem faced by uninformed investors (see Rock 1986) and results in increased offer price discounts. ${ }^{38,}$

Mesma conclusão de KIM e SHIN (2004) ${ }^{39}$, para quem a Rule $10 b-21$ teria resultado em ofertas públicas “menos informadas”, uma vez que, como dito acima, as vendas a descoberto poderiam revelar ao mercado um ativo sobrevalorizado. Conforme sua própria síntese:

\begin{abstract}
"Using a sample of over 3,000 seasoned equity offerings (SEOs) from 1983 to 1998, we test the hypothesis that the U.S. Securities and Exchange Commission's Rule 10b-21, wich disallows the covering of short positions with newly issued SEOs, makes pre-offer stock prices less informative, wich, in turn, causes the new seasoned equity to be priced at a discout. Consistent with the hypotesis, we find
\end{abstract}

\footnotetext{
${ }^{36}$ A esse respeito, Shane A. Corwin comenta: "Prior to the adoption of Rule 10b-21, Safieddine and Wilhelm document unusually high levels of short interest in the pre-offer period and a positive relation between short interest and SEO underpricing. They find no evidence ofa a significant relation after the adoption of Rule 10b-21, supporting the hypothesis that the rule was successful in curbing short selling and reducing underpricing". CORWIN, Shane. The Determinants of Underpricing for Seasoned Equity Offers. Journal of Finance. vol. 58. Outubro de 2003. p. 2252.

${ }^{37}$ GERARD, B.; NANDA, V. Trading and Manipulation aroud Seasoned Equity Offerings. Journal of Finance. vol. 48. 1993. pp. 213-245.

${ }^{38}$ HENRY, T.; KOSKI, J. Short Selling Around Seasoned Equity Offerings, Setembro de 2008. Disponível em: http://papers.ssrn.com/sol3/papers.cfm?abstract_id=972076\&download=yes $>$. Acesso em 10 de novembro de 2015. p. 2

${ }^{39}$ KIM, Kenneth A.; SHIN, Hyun-Han. The Puzzling Increase in the Underpricing of Seasoned Equity Offerings. Financial Review. vol.39. Agosto de 2004. p. 343-365.
} 
that the year the rule went into effect coincides with the year from which we begin observing significant SEO discounts. Further, we find that ex ante uncertainty and SEO discounts are positively related. We also conduct tests specifically related to short selling, and we also consider na exhaustive set of alternative explanations for the discount. Based on all the evidence, we conclude that it is the rule that makes issue discounts larger in the 1990s. ${ }^{40}$,"

Em 1997, a Rule 10b-21 foi substituída pela Rule 105, alterando substancialmente o período de vedação para a realização de vendas a descoberto para os investidores que pretendessem participar da Oferta Pública Subsequente, com a seguinte redação:

“\$242.105 Short selling in connection with a public offering.

(a) Unlawful Activity. In connection with an offering of securities for cash pursuant to a registration statement or a notification on Form 1-A (\$239.90 of this chapter) filed under the Securities Act, it shall be unlawful for any person to cover a short sale with offered securities purchased from an underwriter or broker or dealer participating in the offering, if such short sale occurred during the shorter of:

(1) The period beginning five business days before the pricing of the offered securities and ending with such pricing; or

(2) The period beginning with the initial filing of such registration statement or notification on Form 1-A and ending with the pricing.

(b) Excepted Offerings. This section shall not apply to offerings filed under $\S$ 230.415 of this chapter or to offerings that are not conducted on a firm commitment basis.

(c) Exemptive Authority. Upon written application or upon its own motion, the Commission may grant an exemption from the provisions of this section, either unconditionally or on specified terms and conditions, to any transaction or class of transactions, or to any security or class of securities. By the Commission."

A Rule 105 (em sua primeira versão) passou a proibir que investidores que tenham realizado vendas a descoberto nos últimos cinco pregões antes da data Oferta Pública Subsequente possam cobrir suas posições na com as ações adquiridas na oferta. De forma diferente, a Rule 10b-21, como dito, vedava a cobertura do investidor que tivesse realizado vendas a descoberto

${ }^{40}$ Ibid. p. 343 
entre a data de anúncio da Oferta Pública Subsequente, e a data da oferta, em si. A diferença substancial consistia, portanto, no período de vedação.

Segundo HENRY e KOSKI, "This rule change significantly relaxed the restrictions on short selling around SEOs [Ofertas Públicas Subsequentes]." 41

O aprimoramento da Rule 105 teve início em 2006, quando a SEC submeteu esta regra à audiência pública, visando cercar práticas manipulativas ainda não capturadas pela norma. ${ }^{42}$

Curiosamente, porém, a SEC traz uma justificativa para o aprimoramento da norma um pouco diferente da ideia original de que o short selling seria o fator motivador do underprincing em Ofertas Públicas Subsequentes, cuja leitura torna-se essencial:

"Generally, the offering prices of follow-on and secondary offerings are priced at a discount to a stock's closing price (depending on the Exchange, the closing transaction price, closing bid price, or last sale price) prior to pricing. This discount provides a motivation for a person who has a high expectation of receiving offering shares to capture this discount by aggressively short selling just prior to pricing and then covering the person's short sales at the lower offering price with securities received through an allocation. Covering the short sale with a specified amount of registered offering securities at a fixed price allows a short seller largely to avoid maket risk and usually guarantee a profit. Short sales during the period immediately precending pricing and offering can exert downward pressure upon stock's price.

Some persons may decide to sell short prior to the pricing of an offering beacuse they believe the security is overpriced. This activity provides a true price discovery mechanism for the Market and should be encouraged. Persons who are attempting to capture the offer price discount are not selling short the security beacuse the security is overpriced; thus, they do not contribute to true pricing efficiency. Instead, by selling the security short with the knowledge that they are very likely to be abe to cover their short positions with offertwith offering shares that they are

\footnotetext{
${ }^{41}$ HENRY, T.; KOSKI, Op. cit., p. 2

42 “(...) we have witnessed continued violations of the rule, including a proliferation of trading strategies and structures attempting to accomplish the economic equivalent of the activity that the rule seeks to prevent." Federal Register. Proposed Rules. vol. 71, n. 239. 2006. Diponível em: < http://www.gpo.gov/fdsys/pkg/FR-2006-12-13/pdf/E6-21154.pdf> Acesso em 10 de novembro de 2015.
} 
allocated, these persons may drive down the price despite their true belief regardint the appropriate price for that security. (...) Not only this conduct harmful to the Market and current security holders, but it can reduce the proceeds the issuer or the selling security holder receives from the securities offering. ${ }^{43}$ " (grifamos)

Ou seja, podemos extrair desse posicionamento da SEC que ela compreende que o underpricing é intrínseco às Ofertas Públicas Subsequentes, e que representa um atrativo para aqueles investidores que queiram realizar vendas a descoberto cobrindo suas posições na oferta. Por outro lado, investidores realizando essa estratégia de vendas a descoberto atraídos pelos descontos usualmente praticados em Ofertas Públicas Subsequentes também colaborariam para este mesmo underpricing. Entendese, por esse posicionamento, que o underpricing é, simultaneamente, causa e consequência das vendas a descobertos realizadas no período de precificação destas ofertas.

A SEC não nega que a realização de vendas a descoberto seja saudável para o mercado quando é realizada apenas pela "crença" de que determinado ativo encontra-se sobrevalorizado. Torna-a ilícita, porém, quando tem por objetivo exclusivo o aproveitamento do underpricing, como descrito acima.

E sobre este underpricing intrínseco às Ofertas Públicas Subsequentes, CORWIN bem resume algumas de suas possibilidades.

Como primeira destas, e em linha com o modelo desenvolvido por ROCK (1986) $)^{44}$, entende que o underpricing é necessário para compensar investidores desinformados e assegurar a sua participação em follow-ons. Pelo mesmo motivo, em vista a uma possível assimetria informacional,

\footnotetext{
${ }^{43}$ U.S. SECURITIES AND EXCHANGE COMMISSION. National Exam Program: Risk Alert. Setembro de 2013. Disponível em: <http://www.sec.gov/about/offices/ocie/risk-alert-091713rule105-regm.pdf >. Acesso em: 10 de novembro de 2015. pp. 2-3

${ }^{44}$ ROCK, Kevin. Why new issues are underpriced. Journal of Financial Economics. vol. 15. 1986, pp. 187-212.
} 
quanto mais instáveis as cotações do emissor, maior seriam os descontos praticados..$^{45}$

Para CORWIN, as Ofertas Públicas Subsequentes também exercem uma pressão na cotação das ações por representar uma mudança permanente oferta destes papéis. O mercado, porém, tende a absorver esta informação na data de anúncio da Oferta Pública Subsequente, embora não se possa descartar seus reflexos na data de liquidação da oferta. Nesse contexto, ofertas maiores tenderiam a apresentar descontos maiores, enquanto que ofertas menores, evidentemente, descontos reduzidos. Seus efeitos seriam mais sensíveis em ações com a demanda relativamente inelástica. ${ }^{46}$

Uma vez que a aquisição de ações em Ofertas Públicas Subsequentes tem custos de transação reduzidos, comparativamente às praticadas em bolsa, esta hipótese justificaria descontos maiores para ações em mercados que imponham elevados custos para transferências. ${ }^{47}$

Por fim, CORWIN também aponta que o underpricing em Ofertas Públicas Subsequentes também reflete as práticas convencionais de precificação adotadas pelos underwriters. Como exemplo, amparado pelo estudo elaborado por LEE, LOCHHEAD, RITTER e ZHAO $(1996)^{48}$ nota-

\footnotetext{
${ }^{45}$ CORWIN, Shane. Op. cit., p. 2252

46 "Based on the price pressure hypothesis, I expect larger issues to be more under priced than smaller issues, all else equal. In addition, the effects of price pressure should be most pronounced for securities with relatively inelastic demand.” Op. cit., CORWIN, Shane. p. 2255

47 "Investors who purchase offered shares from underwriter do not pay transaction costs. In the absence of information asymmetries and trading restrictions, Loderer, Sheehan, and Kadlec (1991) argue that this transaction cost savings should allow underwriters to price seasoned offers above the preoffer price by the amount of the one-way transaction cost. Thus, the transaction cost savings hypothesis suggests that seasoned offers by firms with hight transaction costs will be less underpriced (more overpriced) than other offers, all else equals." CORWIN, Shane. Op. cit., p. 2256

${ }^{48}$ LEE, Inmoo. et al. The costs of raising capital. Journal of Financial Research. vol. 19. 1996, p. 59-74.
} 
se que os underwriters tendem a utilizar como parâmetro o preço das últimas ordens de compra praticadas, e não das últimas negociações. ${ }^{49}$

Feitos estes comentários, e retornando às razões de reforma da Rule 105, que se encerrou em 2008, a SEC identificou que a redação então utilizada, que vedava expressamente que as ações adquiridas na Oferta Pública Subsequente fossem destinadas à cobertura de short-sellings abertos nos cinco pregões anteriores à oferta era falha.

Isso porque alguns investidores que haviam realizado vendas a descoberto no período de vedação adquiriam ações no mercado na data da oferta, e também na oferta, justificando que a cobertura de suas posições foi realizada por meio da primeira compra. ${ }^{50}$

Outro esquema seria a abertura de posições a descoberto antes do período de vedação e também dentro deste período, justificando que a cobertura das posições na oferta seria destinada às primeiras negociações. ${ }^{51}$

Para tanto, adaptou a redação da Rule 105 passando a prever que qualquer investidor que tenha realizado vendas a descoberto no período de vedação (salvo a hipótese da cláusula de boa-fé, analisada adiante) não poderia adquirir ações no âmbito da oferta, sem referência à utilização das ações adquiridas para cobertura das posições a descoberto:

\footnotetext{
49 "Lee et. al. (1996) also suggests that SEO underpricing may reflect a tendency for underwriters to price at the closing bid quote rather than the closing transaction price." CORWIN, Shane. Op. cit., p. 2257

50 "Non-compliance (...) such as where investor effects a short sale during the restricted period and subsequently purchases shares both in the offering and in the open Market and asserts that the open market shares were used to cover the short." MATARESE, James. Proposed Amendments to Rule 105 Regarding Short Selling in Connection with Public Offerings. Hedge Fund Alert. Goodwin Procter. Dezembro de 2006. Disponível em:< http://www.goodwinprocter.com/ /media/Files/Publications/Newsletters/Hedge\%20Fund\%20Aler t/2006/Proposed_Amendments to Rule_105_Regarding_Short_Selling in_Connection_with_Pub lic Offerings.pdf $>$. Acesso em 10 de novembro de 2015.

51 "Another of these "peripheral" contexts involves shorting both prior to the restricted period and during the restricted period and then purchasing securities in the offering to cover the initial short sale". Ibid. p.2
} 
“(a) Unlawful activity. In connection with an offering of equity securities for cash pursuant to a registration statement or a notification on Form 1-A (\$239.90 of this chapter) or Form 1-E (\$239.200 of this chapter) filed under the Securities Act of 1933 ('offered securities'), it shall be unlawful for any person to sell short (as defined in $\$ 242.200(a)$ ) the security that is the subject of the offering and purchase the offered securities from an underwriter or broker or dealer participating in the offering if such short sale was effected during the period ("Rule 105 restricted period") that is the shorter of the period:

(1) Beginning five business days before the pricing of the offered securities and ending with such pricing; or

(2) Beginning with the initial filing of such registration statement or notification on Form 1-A or Form 1-E and ending with the pricing." (grifamos)

Ainda, havia uma considerável dificuldade em coibir operações de cobertura cruzada, onde determinado investidor que tenha realizado vendas a descoberto adquiria privadamente as posições necessárias para a cobertura de outro investidor participante do esquema ${ }^{52}$. Para tanto, incluíram a previsão expressa do conceito de "contas separadas", conforme:

"(2) Separate accounts. Paragraph (a) of this section shall not prohibit the purchase of the offered security in an account of a person where such person sold short during the Rule 105 restricted period in a separate account, if decisions regarding securities transactions for each account are made separately and without coordination of trading or cooperation among or between the accounts."

Ou seja, a contrário senso, se as decisões de investimento de diferentes contas fossem determinadas por um mesmo investidor, haveria a incidência expressa da vedação à participação da oferta caso uma dessas tenha realizado vendas a descoberto no período de vedação.

O conceito de "contas separadas" por sua vez, também dependerá da análise dos fatos e circunstâncias, sendo que a SEC faz uso dos seguintes parâmetros para a sua determinação:

a) as contas possuem investimentos, estratégias e objetivos distintos;

\footnotetext{
52 "The most troublesome circumstances to the SEC, however, are those where investors more clearly seek to engage in short sales in advance of a public offering in direct contravention to the rule through a number of post-offering cross trading activities." Ibid. p. 2
} 
b) os responsáveis por cada conta não coordenam negociações entre estas mesmas contas;

c) há restrições ao trafego de informações entre estas contas, não compartilhando as informações sobre as decisões de investimento;

d) cada conta contabiliza seus lucros e prejuízos individualmente;

e) valores mobiliários não são alocados entre estas contas; e

f) os responsáveis pela gestão de múltiplas contas em uma mesma entidade, ou afiliadas, e contas de uma mesma titularidade, não são autorizados a executar negociações destes valores mobiliários entre estas contas, nem pré-aprovar as decisões de investimento destas contas. ${ }^{53}$

Para não inviabilizar a indústria de investment companies, criou uma exceção a sua atuação para séries ou afiliadas diferentes. Como veremos adiante, essa regra ficará mais clara no momento em que visualizarmos dispositivo semelhante previsto para os fundos de investimento brasileiros na Instrução CVM 530/12.

“(3) Investment companies. Paragraph (a) of this section shall not prohibit an investment company (as defined by Section 3 of the Investment Company Act) that is registered under Section 8 of the Investment Company Act, or a series of such company (investment company) from purchasing an offered security where any of the following sold the offered security short during the Rule 105 restricted period:

(i) An affiliated investment company, or any series of such a company; or

(ii) A separate series of the investment company."

${ }^{53}$ U.S. SECURITIES AND EXCHANGE COMMISSION. National Exam Program: Risk Alert. Setembro de 2013. p. 2-3 
Por fim, esta reforma da Rule 105 incluiu a denominada "cláusula de boa-fé", que autoriza a participação na oferta por investidores que tenham realizado vendas a descoberto no período vedado, porém coberto suas posições até o último pregão antes da data de precificação da oferta.

"(b) Excepted activity-(1) Bona fide purchase. It shall not be prohibited for such person to purchase the offered securities as provided in paragraph (a) of this section if:

(i) Such person makes a bona fide purchase(s) of the security that is the subject of the offering that is:

(A) At least equivalent in quantity to the entire amount of the Rule 105 restricted period short sale(s);

(B) Effected during regular trading hours;

(C) Reported to an "effective transaction reporting plan" (as defined in $\S$ $242.600(b)(22)) ;$ and

(D) Effected after the last Rule 105 restricted period short sale, and no later than the business day prior to the day of pricing; and

(ii) Such person did not effect a short sale, that is reported to an effective transaction reporting plan, within the 30 minutes prior to the close of regular trading hours (as defined in $\$ 242.600(b)(64)$ ) on the business day prior to the day of pricing."

A razão pela qual existe esta cláusula de boa-fé é a existência das overnight offerings nos EUA, Ofertas Públicas Subsequentes realizadas em dois dias após o seu anúncio. Assim, caso algum investidor que venha realizando vendas a descoberto com ações de emissão dessa companhia queira participar dessa oferta, poderá se cobrir a tempo para tanto. ${ }^{54} 55$

\footnotetext{
54 "The SEC has acknowledged that this element of the exception may prevent its use in a "truly 'overnight deal' when an offering commences after the close of regular trading on the day of pricing" because such person will not have time to effect a qualifying covering purchase." COHEN, Alexander F. et al. What's the Deal with Regulation M. Latham \& Watkins Capital Markets Group. $\mathrm{n}^{\circ}$ 1531. Maio de 2013. Disponível em: < https://www.lw.com/thoughtLeadership/regulation-mguide-faq > Acesso em: 10 de novembro de 2015. p. 16

${ }^{55}$ U.S. SECURITIES AND EXCHANGE COMMISSION. Release No 34-56206. File No. S7-20-06. Disponível em: <https://www.sec.gov/rules/final/2007/34-56206.pdf> Acesso em: 10 de novembro de 2015. p. 13.
} 


\section{IV.2 Enforcement da SEC}

Desde janeiro de 2010, podemos considerar que o enforcement da Rule 105 tornou-se uma das prioridades da $\mathrm{SEC}^{56}$, parte de sua política de tolerância zero.

Segundo o diretor da área do enforecement da SEC, Andrew Ceresney, "[t]he benchmark of an effective enfocerment program is zero tolerance for any securities law violations, including violations that do not require manipulative intent." ${ }^{57}$

Em sua atuação sancionadora, a SEC firmou o entendimento de que as violações à Rule 105 não exigem a intenção fraudulenta ou intenção do investidor $^{58}$. Ainda, a adoção de medidas preventivas após a violação da Rule 105 , não teria o condão de absolver o investidor investigado. ${ }^{59}$

Assim, uma vez que a norma não exige a intenção, torna-se crucial para que o investidor (especialmente aos participantes intermediários):

a) implementar políticas e procedimentos destinados ao cumprimento da Rule 105;

56 "Since January 2010, violations of Rule 105 have been major focus of SEC enforcement activity." MARX, Daniel; WOOD, Lisa. SEC Enforcement Year in Review: Auctions and Issues from 2013. The Investment lawyer, covering legal and regulatory issues of aset management. vol. $21 . \mathrm{n}^{\circ} 1$. Janeiro de 2014. p. 10

57 "SEC charges 23 Firms with Short Selling Violations in Crackdown on Potential Manipulation in Advance of Stock Offerings" U.S. SECURITIES AND EXCHANGE COMMISSION. Press Release 2013-182. Setembro de 2013. Disponível em: http://www.sec.gov/News/PressRelease/Detail/PressRelease/1370539804376>. Acesso em 10 de novembro de 2015.

58 "Moreover, beacuse Rule 105 imposes strict liability, once a violation has been established, it is no defense to say that the person or entity who broke the law acted without scienter or fraudulent intente." MARX, Daniel; WOOD, Lisa. Op. cit., p. 10

59 "After-the-fact remediation would not absolve a firm or individual from the violation of Rule 105." U.S. SECURITIES AND EXCHANGE COMMISSION. National Exam Program: Risk Alert. p.4 
b) monitorar a atividade de vendas a descoberto;

c) treinar pessoal estratégico par ao cumprimento da norma; e

d) aprimorar os procedimentos necessários com a implementação de rotinas de monitoramento e testes. ${ }^{60}$

Para eventuais cálculos de ressarcimento (disgorgement) das vantagens auferidas pelo investidor investigado, ainda que por meio diverso dos usuais termos de compromisso (settlement), a SEC vale-se da soma (i) do lucro da venda a descoberto, calculada pela diferença do preço vendido a descoberto e do valor adquirido na oferta, e (ii) do lucro da oferta, uma medida do lucro auferido em detrimento do ofertante, calculado pela diferença entre o preço da oferta e o preço médio praticado em mercado na mesma data. ${ }^{61}$

\footnotetext{
60 "As the Rule does not require intente, it is crucial for a firm to: Implement policies and procedures reasonably designed to comply with the Rule; Monitor the short sale activities of the firm in order to spot potential problems before they arise; Train key personnel regardin compliance with the Rule; and Improve procedures as necessary following routine monitoring and testing." Op. cit. MARX, Daniel; WOOD, Lisa. SEC Enforcement Year in Review: Auctions and Issues from 2013, p. 15 ${ }^{61 " A}$ core element of this program is the uniform formula for disgorgement: typically, a combination of (i) the short profit, wich is based upon the difference between the short proce and the cover price, and (ii) the offering profit, a measure of the improperly obtained benefit form the offering, which is based upon the difference between the offering price and the volume-weighted average price (VWAP) on the same day." Ibid. p.10
} 


\section{Capítulo IV - Experiência brasileira com regras de proteção a formação de preço em ofertas públicas}

\section{IV.1 A edição da Instrução CVM 530/2012}

Entre os anos de 2010 e 2011, participantes do mercado encaminharam à CVM correspondências buscando iniciar o debate relativo ao tratamento das vendas a descoberto de ações realizadas por investidores no contexto de Ofertas Públicas Subsequentes, espelhando-se na regulamentação adotada pelos EUA por meio da Rule 105.

Avançados os estudos, em 03 de agosto de 2012 a Superintendência de Desenvolvimento de Mercado - SDM instaurou a Audiência Pública ${ }^{\circ}$ 04/12 (“Audiência Pública”), propondo a regulamentação regras de proteção à formação de preços subsequentes nos moldes então praticados pela Rule 105.6263

Para tanto, contou com o relatório suporte da Assessoria de Análise e Pesquisa - ASA, denominado "Existência de short-selling anormal no curso das ofertas de companhias com ações negociadas e o seu impacto no preço da oferta".

Por meio deste relatório, analisou a atividade de short selling nas seguintes janelas temporais: [D-1 a D-3]; [D-1 a D-5]; [D-1;AM]; e [D-1 a Protocolo], sendo "D” o dia de anúncio de início de negociação; “AM” o dia

\footnotetext{
62 A Audiência Pública encontra-se disponível em: <http://www.cvm.gov.br/audiencias_publicas/ap_sdm/2012/sdm0412.html> Acesso em: 10 de novembro de 2015

${ }^{63}$ SUPERINTENDÊNCIA DE DESENVOLVIMENTO DE MARCADO. Audiência Pública SDM $\mathrm{n}^{\mathrm{O}} \quad$ 04/2012. Disponível em: <http://www.cvm.gov.br/export/sites/cvm/audiencias_publicas/ap_sdm/anexos/2012/sdm0412edital.pdf $>$ Acesso em 10 de novembro de 2015.
} 
da publicação do Aviso ao Mercado pela companhia emissora contando o cronograma da oferta; e "Protocolo" a data de protocolo da oferta ${ }^{64}$.

Visualiza-se pelo seguinte quadro:

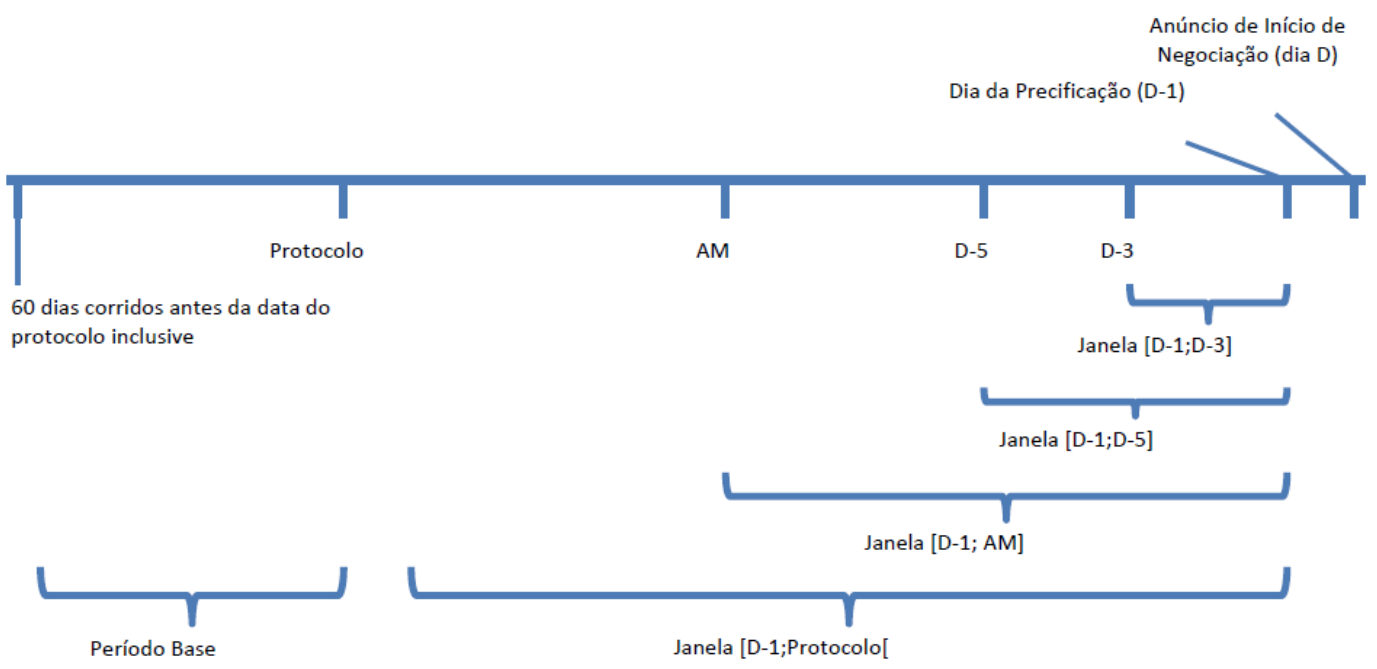

Utilizando-se de uma amostra de 39 Ofertas Públicas Subsequentes realizadas por companhias brasileiras entre janeiro de 2007 e julho de 2011, a ASA chegou às seguintes conclusões: ${ }^{66}$

a) em $82 \%$ da amostra foi identificada a existência de short-selling anormal nas janelas [D-1 a D-3]; [D-1 a D-5], datas mais próximas da oferta;

b) em $74 \%$ da amostra foi identificada foi identificada a existência de short-selling anormal em todas as janelas; e

\footnotetext{
${ }^{64}$ Conforme informado na Audiência Pública, nos casos em que houve protocolização na Associação Brasileira das Entidades dos Mercados Financeiro e de Capitais - ANBIMA antes da CVM, a data de protocolo utilizada equivale àquela que ocorreu primeiro.

65 Gráfico constante do Edital da Audiência Pública, disponível em: <http://www.cvm.gov.br/export/sites/cvm/audiencias_publicas/ap_sdm/anexos/2012/sdm0412edital.pdf > Acesso em: 10 de novembro de 2015.

${ }^{66}$ A amostra inicial fora de 64 ofertas. A ASA, porém, optou por excluir algumas ofertas por motivos diversos, como a quantidade substancial de ADRs, distribuição de juros sobre o capital próprio em períodos próximos a oferta, dentre outros.
} 
c) em $59 \%$ da amostra o short-selling anormal foi progressivo.

Quanto ao impacto deste short-selling na precificação da oferta, relacionou as estas negociações realizadas nas janelas de [D-1 a D-3]; [D-1 a D-5] a um maior underpricing. ${ }^{67}$

Diante destas conclusões, a SDM corroborou as preocupações manifestadas por participantes do mercado de capitais brasileiro, de que a ausência de regras de proteção à formação de preços em Ofertas Públicas Subsequentes poderia desestimular a realização de novas captações no mercado brasileiro.

Assim, seguiu à edição da Instrução CVM 530/12, sobre a qual realizaremos alguns comentários.

O caput do artigo $1^{\circ}$, traz a redação adotada pela SEC após a reforma da Rule 105, em 2008, desvinculando a ideia de cobertura dos ativos adquiridos na oferta, tendo em vista as estratégias então adotadas pelo mercado para burlar da literalidade da norma.

Seu período de vedação abrange, também, os cinco pregões anteriores à data de fixação do preço da oferta, período usualmente adotado no bookbuilding.

"Art. $1^{o}$ Fica vedada a aquisição de ações, no âmbito de ofertas públicas de distribuição de ações, por investidores que tenham realizado vendas a descoberto da ação objeto na data da fixação do preço da oferta e nos 5 (cinco) pregões que a antecedem."

\footnotetext{
${ }^{67}$ Conforme informado na Audiência Pública, em relação ao impacto da intensidade de short-selling sobre o preço da oferta (o retorno), os resultados das regressões sinalizaram uma relação negativa entre o indicador relativo de short-selling e a variação do preço das ações para as janelas [D-1 a D3]; [D-1 a D-5] (Anexos IV e V), considerando nível de significância de 5\%. A estatística t dos coeficientes dessa variável, em ambos os períodos, é inferior a $5 \%$.
} 
Uma vez que a CVM não se utiliza de nenhuma outra instrução para a definição de "vendas a descoberto", a exemplo do que faz a SEC por meio da Rule 17 CFR 242.200, a Instrução CVM 530/12 a traz sua própria redação.

“ $\$ 1^{\circ}$ Para os efeitos desta instrução, são consideradas vendas a descoberto aquelas realizadas por investidores que não sejam titulares das ações, ou cuja titularidade resulte de empréstimo ou outro contrato de efeito equivalente."

Ou seja, traz uma disposição genérica, que nos permite enquadrar, como modalidades de vendas a descoberto, tanto o "covered short selling", quanto o "naked short selling", acima anlisados.

Ainda, a Instrução CVM 530/12 consolida os conceitos de "separate accounts" e a exceção trazida às "investment companies" pela Rule 105, de modo a não inviabilizar operações legítimas realizadas por fundos de investimentos sob uma mesma gestão.

"§ $2^{\circ}$ Para os efeitos desta instrução, são consideradas operações de um mesmo investidor as vendas a descoberto $e$ as aquisições de ações realizadas em seu próprio nome ou por meio de qualquer veículo cuja decisão de investimento esteja sujeita a sua influência.

$\S 3^{\circ}$ Fundos de investimento cujas decisões de investimento sejam tomadas pelo mesmo gestor não serão considerados como um único investidor para efeito do disposto neste artigo, desde que as operações estejam enquadradas nas respectivas políticas de investimento de cada fundo."

A norma traz ainda duas importantes exceções, de igual forma à Rule 105.

" $\$ 4^{\circ}$ A vedação prevista no caput não se aplica nos seguintes casos:

I - operações realizadas por pessoas jurídicas no exercício da atividade de formador de mercado da ação objeto da oferta, conforme definida na norma especifica; $e$

II - operações posteriormente cobertas por aquisição em mercado da quantidade total de ações correspondente à posição a descoberto até, no máximo, 2 (dois) pregões antes da data de fixação do preço da oferta." 
A primeira destas leva em consideração que os formadores de mercado (Coordenador Líder), que pela sua relação com a oferta, evidentemente, não faria uso das vendas a descoberto para prejudicar a formação de preços.

Na segunda exceção, trata-se da "clausula de boa fé" prevista na Rule 105 para possibilitar a participação de investidores "surpreendidos" com as overnight offerings. Fica, porém, deslocada da realidade brasileira, uma vez que esta modalidade de ofertas não existe no nosso mercado.

Ainda no âmbito da Audiência Pública, a BM\&FBOVESPA, concordando com o texto da norma então proposto preocupou-se apenas com o momento de verificação das vendas a descoberto, questionando se este seria o momento da inserção da oferta no sistema ou após a sua liquidação. Isso porque, caso a BM\&FBOVESPA fosse responsável por vedar a aquisição de ações na oferta por investidores que tenham realizado vendas a descoberto no período de vedação, em função do delay existente entre o momento da ordem e o da liquidação, alguns investidores poderiam não ser apurados pelo seu filtro.

Um dos exemplos seria a prática do naked short selling, onde o investidor sequer teria realizado o empréstimo das ações objeto da oferta, dificultando a constatação da infração.

A esse respeito, a CVM frisou que não exigirá a implementação de qualquer bloqueio prévio que requeira a verificação das posições dos investidores, sendo a análise acerca dessas posições realizada a posteriori. Ou seja, a BM\&FBOVESPA não será responsável pela implementação dos filtros necessários a verificação da incidência da Instrução CVM 530/12.

Também motivada por um questionamento da BM\&FBOVESPA, a CVM esclareceu que os comandos contidos na Instrução CVM 530/12 são 
dirigidos aos investidores, e não às instituições intermediárias ou à entidade administradora de mercado organizado.

\section{IV.2 Análise do Processo Administrativo CVM RJ2013/6775}

No âmbito do Processo Administrativo CVM RJ2013/6775 ("PAS CVM RJ2013/6775"), a CVM averiguou a possível ocorrência de irregularidades, à luz da Instrução CVM 530/12, no âmbito da Oferta Pública Subsequente de ações de emissão da Marfrig S.A., ocorrida em 04 de dezembro de 2012 ("Marfrig" e "Oferta Marfrig").

Nessa oferta, o valor de emissão das ações foi fixado em $\mathrm{R} \$ 8,00$, valor $11,6 \%$ abaixo da cotação de fechamento do mercado no pregão da data de encerramento do bookbuilding.

Após o encaminhamento dos filtros realizados pela Superintendência de Relações com o Mercado e Intermediários - SMI, a Superintendência de Registro de Valores Mobiliários - SRE identificou que dois participantes da Oferta Marfrig teriam realizado vendas a descoberto no período de vedação, em infração à Instrução CVM 530/12.

Um destes investidores, possuía uma condição incomum. Embora fosse detentor de 147.400 ações de emissão da Marfrig, toda esta participação encontrava-se mantida em empréstimos no então Banco de Títulos CBLC BTC, razão pela qual a SRE, identificando o movimento de aluguel e venda de 11.700 ações no período vedado, a caracterizou como uma venda a descoberto.

A SMI, por sua vez, admitiu que, de fato:

"Para todos os efeitos legais, a condição para um investidor ser considerado como titular das ações em uma determinada data é que o mesmo esteja registrado com 
saldo positivo na depositária ou no livro de acionistas mantido pelo prestador de serviços de escrituração da Companhia. Posições doadoras de ações registras no BTC não atendem a essa condição"68

Por outro lado, ponderou que:

"pela atuação simultânea doadora e tomadora no BTC, com saldo positivo doador, pode ser considerado, do ponto de vista econômico, que o investidor tinha características de um acionista da companhia, a despeito de legalmente ele não estar nessa condição. Deve-se também considerar que o [investidor] poderia ter encerrado parte de seus contratos em que atuava como doador e ter realizado a venda das ações, visto que os contratos previam essa possibilidade de encerramento antecipado. Os resultados da situação hipotética e da situação efetivamente ocorrida, em termos econômicos, seriam idênticos." $" 69$

Dada a divergência, a SRE solicitou um parecer à Procuradoria Federal Especializada - PFE, que se manifestou no mesmo entendimento da SMI, defendendo a essência econômica contida na norma. Pesou, em sua fundamentação, que investidor assumiu o risco de flutuação destas ações previamente às operações de venda a descoberto, característica diversa do “manipulador” enquadrado pela Instrução CVM 530/12.

Assim, a SRE não prosseguiu com as investigações em relação a este investidor.

Ainda neste mesmo processo, a gestora de dois fundos de investimento que realizaram vendas a descoberto no período vedado e participaram da Oferta Marfrig firmou, 20 de agosto de 2013, termo de compromisso pelo qual se comprometeu a pagar $\mathrm{R} \$ 80.000,00$ em favor da CVM, pela incidência na conduta vedada pela Instrução CVM 530/12. ${ }^{70}$

\footnotetext{
${ }^{68}$ PAS CVM RJ2013/6775, fl. 335

${ }^{69}$ Ibid. fl. 335

${ }^{70} \mathrm{O}$ Parecer elaborado pelo Comitê de Termo de Compromisso não indica os valores envolvidos nas operações, nem supostos ganhos. Disponível em:<http://www.cvm.gov.br/export/sites/cvm/decisoes/anexos/0010/8870-0.pdf > Acesso em 10 de novembro de 2015.
} 


\section{IV.3 A aplicabilidade da Instrução CVM 08/79}

Conforme justificou a própria SEC quando da reforma da Rule 105, suas alterações têm por objetivo resguardar a integridade dos aumentos de capital e proteger os emissores de atividades manipulativas. ${ }^{71}$

Ainda, a SEC sustenta claramente que a Rule 105 tem caráter preventivo, razão pela qual independe de qualquer intenção manipulativa do vendedor a descoberto para a sua incidência. ${ }^{72}$

Aceitamos estes mesmos fundamentos para a introdução da Instrução CVM 530/2012, que na Audiência Pública manifestou que esta regra seguiria os moldes adotados nos EUA para prevenir a manipulação artificial dos preços.

Assim, a CVM tem por objetivo "contribuir para restaurar condições de apreçamento livres de forças artificiais, de modo que os preços das ofertas resultem dos movimentos naturais de procura e oferta, o que é um estímulo à realização de ofertas públicas por companhias já registradas"73.

Lembrando que, nos termos da Instrução CVM 08/79, são previstos tipos penais para figuras usualmente relacionadas ao conceito genérico de práticas manipulativas, quais sejam:

\footnotetext{
71 "The Securities and Exchange Commission ('Commission') is adopting amendments to Regulation $M$ to further safeguard the integrity of the capital raising process and protect issuers from manipulative activity that can reduce issuer's offering proceeds and dilute security holder value. The amendments eliminate the covering element of the former rule." U.S. SECURITIES AND EXCHANGE COMMISSION. Release No 34-56206. File No. S7-20-06. p. 1.

72 "Rule 105 is prophylactic. Thus, its provisions apply irrespective of a short seller's intent." Ibid. p.2.

73 Conforme o Relatório da Audiência Pública. Disponível em:<http://www.cvm.gov.br/export/sites/cvm/audiencias_publicas/ap_sdm/anexos/2012/sdm0412relatoriosdm.pdf> Acesso em 10 de novembro de 2015.
} 
“a) condições artificiais de demanda, oferta ou preço de valores mobiliários aquelas criadas em decorrência de negociações pelas quais seus participantes ou intermediários, por ação ou omissão dolosa provocarem, direta ou indiretamente, alterações no fluxo de ordens de compra ou venda de valores mobiliários;

b) manipulação de preços no mercado de valores mobiliários, a utilização de qualquer processo ou artifício destinado, direta ou indiretamente, a elevar, manter ou baixar a cotação de um valor mobiliário, induzindo, terceiros à sua compra e venda;

c) operação fraudulenta no mercado de valores mobiliários, aquela em que se utilize ardil ou artifício destinado a induzir ou manter terceiros em erro, com a finalidade de se obter vantagem ilícita de natureza patrimonial para as partes na operação, para o intermediário ou para terceiros" (grifos originais)

Quanto à criação de condições artificiais de demanda, oferta ou preço de valores mobiliários, bem define o então Diretor Relator Luiz Antonio de Sampaio Campos, no âmbito do Processo Administrativo Sancionador CVM 02/99, julgado em 06 de setembro de 2010:

\begin{abstract}
"Na criação artificial de condições de demanda, oferta ou preço de valores mobiliários, o prejuízo potencial dirige-se à generalidade dos detentores de determinado valor mobiliário e ao mercado como um todo, que receberiam uma sinalização fictícia a respeito de determinado valor mobiliário. Nesse mesmo tipo de operação, entendo que não há ganho ou perda entre as partes que participam da criação dessas condições artificiais, $\underline{\underline{\mathbf{s} \tilde{o}}}$ operacões que, na verdade, não existiriam em essência, não fosse a pretensão de se criar um falso mercado, um falso parâmetro de preço ou volume. Percebe-se, portanto, que deste tipo de infração resultariam prejuízos a um número considerável de investidores, e, por que não dizer, à estabilidade e integridade do mercado." (grifamos)
\end{abstract}

DOS SANTOS, OSÓRIO e WELLISCH, concluem desta passagem:

\begin{abstract}
"O tipo não exige, portanto, a busca ou a obtenção de qualquer resultado material para o agente, constituindo ilícito administrativo de mera conduta. A norma, neste particular, não pretende coibir desejo ou obtenção de vantagem indevida, mas, sobretudo, tutelar a integridade e o regular funcionamento do mercado de valores mobiliários, para que não haja um falso parâmetro, uma sinalização fictícia para todo o público investidor em potencial, como indica o precedente antes referido. ",74
\end{abstract}

\footnotetext{
74 DOS SANTOS, Alexandre Pinheiro; OSÓRIO, Fábio Medina. WELLISCH, Julya Sotto Mayor. Mercado de Capitais Regime Sancionador. Saraiva. 2015. p. 116-117.
} 
Ensinam, também, que a "criação de condição artificial de demanda, oferta e preço" difere-se da "manipulação de mercado" pois este último utiliza-se de manobras artificiais destinadas a elevar, manter ou baixar a cotação de um valor mobiliário com a finalidade maior de induzir terceiros a adquirir ou alienar papéis sobrevalorizados ou subavaliados. ${ }^{75}$

Comparando a redação dada a estes tipos na Instrução CVM 08/79, nota-se, também, que a "manipulação de mercado" se destina a afetação do preço de determinado valor mobiliário, enquanto que a "criação de condições artificiais", não somente o preço, como também a demanda e oferta. ${ }^{76}$

O que nos parece, portanto, é que as estratégias "manipulativas" empregadas por investidores que se utilizem de vendas a descoberto para afetar a precificação de determinada Oferta Pública Subsequente e obter vantagem no momento da cobertura de suas posições, aproximam-se mais do tipo descrito como criação de "condições artificiais de demanda, oferta ou preço de valores mobiliários". Isso porque a "manipulação de mercado" destina-se a induzir terceiros à compra ou venda, elemento não exigido pela "criação artificial de condições de demanda, oferta ou preço de valores mobiliários"

A "operação fraudulenta", também merece nossa atenção pois o investidor que "ataca" a precificação de uma Oferta Pública Subsequente por meio de vendas a descoberto, de fato, induz o Coordenador Líder e o

\footnotetext{
75 'Diferentemente da 'criação de condição artificial de demanda, oferta e preço', no ilícito de manipulação de mercado a utilização de manobras artificiais destinadas a elevar, manter ou baixar a cotação de um valor mobiliário tem a finalidade maior de induzir terceiros a adquirir ou alienar os papéis sobrevalorizados ou subavaliados". Ibid. p.118.

76 "Além disso, e como a própria denominação dos ilícitos indica, a criação de condições artificiais é mais ampla do que a manipulação. Aquela abrange não apenas os preços, como ocorre com a manipulação, mas também a demanda e a oferta dos títulos." Ibid. p.118.
} 
Ofertante a erro ao valerem-se de parâmetros de mercado artificialmente alterados para precificar a oferta.

Interpretações à parte, nos parece claro que a CVM, anteriormente à edição da Instrução CVM 530/12, já dispunha de tipos penais para sancionar os "ataques" a precificação de Ofertas Públicas Subsequentes, nos moldes da estratégia então descrita.

A Instrução CVM 530/12, porém, além de ter evidente caráter preventivo, à exemplo da Rule 105, também instrumentaliza a CVM de meios mais eficazes para coibir condutas danosas do que os tipos genéricos descritos na Instrução CVM 08/79.

Nesse sentido, comenta a Financial Industry Regulatory Authority FIRA que a SEC, quando da edição da Rule 10b-21, acreditava que esta norma seria importante tendo em vista a dificuldade de produção de provas demonstrando o intuito manipulativo daqueles investidores que, artificialmente, atacavam a precificação de Ofertas Públicas Subsequentes. ${ }^{77}$ Do mesmo modo, entendemos que a Instrução CVM 530/12 tem a mesma serventia para o mercado de capitais brasileiro.

Cabe, também, uma outra diferenciação relevante. Conforme DOS SANTOS, OSÓRIO e WELLISCH, os tipos previstos na Instrução CVM 08/79 não seriam aplicáveis a condutas meramente culposas, ainda que extensíveis às hipóteses de dolo eventual. ${ }^{78}$

\footnotetext{
77 "The Commission believes that the Rule will serve an important purpose by avoiding the difficult proof problems involved in demonstrating manipulative purpose." Op. cit. FINANCIAL INDUSTRY REGULATORY AUTHORITY. 88-62 SEC Adopts Rule 10b-21 Prohibiting Shorting into Secondaries.

78 "O que não parece juridicamente viável, em qualquer dos ilícitos aqui tratados - mesmo para aqueles que a letra do tipo especificamente considerado não exija o dolo - é a condenação por uma atuação ou participação meramente culposa." DOS SANTOS, Alexandre Pinheiro; OSÓRIO, Fábio Medina. WELLISCH, Julya Sotto Mayor. Op. cit., p.116
} 
Porém, uma vez que a Instrução CVM 530/12 assume-se no espírito preventivo da Rule 105, não seria necessária a verificação de elementos como dolo ou culpa para a caracterização da conduta vedada, diferentemente do que ocorre com a Instrução CVM 08/79.

Por fim, em semelhança, tanto a Instrução CVM 530/12, quanto a Instrução CVM 08/79 definem como "grave", para os efeitos do parágrafo $3^{\circ}$ do artigo 11 da Lei 6.385/1976, eventuais infrações aos tipos descritos. 


\section{Conclusão}

O estudo das regras de proteção à formação de preços em Ofertas Públicas Subsequentes é indissociável de sua finalidade econômica, sem a qual se tornariam meros caprichos dos reguladores.

Não podemos, no entanto, assumir que estas regras atendam o seu objetivo - de reduzir o underpricing manipulativo em ofertas públicas - haja vista as relevantes posições doutrinárias que questionam supostos efeitos colaterais. O principal, como vimos, seria o fato de que o mercado tornar-seia mais "desinformado" quanto a um possível sobrepreço de determinada ação, uma vez que estas normas trazem restrições às vendas a descoberto.

Por essa razão, abraçamos a análise jurídica da norma em si, pois não nos cabe, neste momento, questionar a sua existência. E para esta análise, nos focamos na Rule 105, pela sua inspiração prestada à Instrução CVM 530/12, bem como pelos anos de evolução acumulados, desde a sua introdução, ainda na forma da Rule 10b-21.

Ao longo destes anos, os reguladores vêm reformando as regras de proteção à formação de preços sempre na tentativa de capturar aqueles investidores "malfeitores" que descobrem saídas para burlarem a norma, e atacarem a precificação das Ofertas Públicas Subsequentes em seu próprio interesse.

Parecem, também, ter a total ciência de que a venda a descoberto (short selling) é um instrumento vital para a correta precificação de valores mobiliários negociados em bolsa. Não à toa, a Rule 105 evoluiu para um período de vedação reduzido, se comparado à Rule $10 b$-21, e para a inserção de uma clausula de boa-fé, que permite que investidores que vinham 
realizando vendas a descoberto adquiram ações em mercado e participem da oferta.

A experiência brasileira com a Instrução CVM 530/12, por sua vez, ainda é reduzida, mas a norma carrega o mérito de ser absolutamente semelhante à Rule 105, trazendo um norte definido desde a sua implementação. Foram 12 Ofertas Públicas Subsequentes desde a sua edição até a presente data ${ }^{79}$ o que pode ser considerado até uma amostra razoável, mas somente em um processo, o PAS CVM RJ2013/6775 temos um precedente pré-sancionador da Instrução CVM 530/12.

À realidade do mercado de capitais brasileiro, não podemos deixar de notar algumas semelhanças entre as estratégias convencionais compelidas pela Instrução CVM 530/12, com as "práticas manipulativas" lato sensu, também combatidas pela Instrução CVM 08/79.

A Instrução CVM 530/12, porém, tem evidente caráter preventivo, definindo claramente as condutas tidas como ilícitas, não exigindo, para o seu enquadramento, qualquer intenção manipulativa, como o faz a Instrução CVM 08/79.

Definições à parte, esperamos que em um futuro reaquecimento do mercado de equity brasileiro, a Instrução CVM 350/12 ganhe uma maior relevância no enforcement da CVM, assim o como a SEC vem priorizando a aplicação da Rule 105 desde o ano de 2010.

\footnotetext{
${ }^{79}$ Considerando somente as realizadas pelo rito previsto na Instrução CVM 400/03, constam as Ofertas Públicas Subsequentes da Minerva S.A, Marfrig S.A., Equatorial Energia S.A., Aliansce Shopping Centers S.A., Estácio Participações S.A., Multiplan Empreendimentos Imobiliários S.A., BHG S.A., Abril Educação S.A. (atual Somos Educação S.A.), Iguatemi Empresa de Shopping Centers S.A., Tupy S.A., Via Varejo S.A., Oi S.A. e Telefonica Brasil S.A.
} 


\section{Bibliografia}

ASSESSORIA DE ANÁLISE E PESQUISA. Existência de short-selling anormal no curso das ofertas de companhias com ações negociadas e o seu impacto no preço da oferta. 2012. Disponível em:< http://www.cvm.gov.br/export/sites/cvm/audiencias_publicas/ap_sdm/anex os/2012/sdm0412-relatorio.pdf $>$. Acesso em 10 de novembro de 2015.

CHEN, Zhaohui. et al. Another Look at Bookbuilding, Auctions, and the future of the IPO Process. Journal of Applied Corporate Finance. vol. 26. $\mathrm{n}^{\mathrm{o}}$ 2. 2014.

CODORNIZ, Gabriela; PATELLA, Laura (coord.). Comentários à Lei do Mercado de Capitais - Lei n ${ }^{\circ}$ 6.385/76. São Paulo: Quartier Latin, 2015.

COMISSÃO DE VALORES MOBILIÁRIOS. Comunicado IOSCO: iniciativas que impõem restrições a vendas a descoberto (Short Selling). Disponível em: <http://www.cvm.gov.br/noticias/arquivos/2008/200810031.html>. Data de acesso 08 de outubro de 2015.

COMISSÃO DE VALORES MOBILIÁRIOS. CVM publica Instrução 461, que disciplina os mercados regulamentados de valores mobiliários. Disponível em: 〈http://www.cvm.gov.br/noticias/arquivos/2007/200710231.html >. Data de acesso 02 de novembro de 2015.

COHEN, Alexander F. et al. What's the Deal with Regulation M. Latham \& Watkins Capital Markets Group. no 1531. Maio de 2013. Disponível em: < https://www.lw.com/thoughtLeadership/regulation-m-guide-faq $>$ Acesso em: 10 de novembro de 2015. 
CORWIN, S. The Determinants of Underpricing for Seasoned Equity Offers. The Journal of Finance, vol. 58, no 5.2003.

CULP, Christopher L., HEATON, J.B. The Economics of Naked Short Selling: Naked shorting is little diferente from permissible shorting. Cato Institute. 2008.

DOS SANTOS, Alexandre Pinheiro; OSÓRIO, Fábio Medina. WELLISCH, Julya Sotto Mayor. Mercado de Capitais Regime Sancionador. Saraiva, 2015.

EIZIRIK, Nelson, et al. Mercado de Capitais: Regime Jurídico. Rio de Janeiro: Renovar, 2008.

EIZIRIK, Nelson, et al. Mercado de Capitais: Regime Jurídico. Rio de Janeiro: Renovar, 2011.

FINANCIAL INDUSTRY REGULATORY AUTHORITY. 88-62 SEC Adopts Rule 10b-21 Prohibiting Shorting into Secondaries. 1988. Disponível em: < http://finra.complinet.com/en/display/display_main.html?rbid=2403\&eleme nt_id=899\&print=1>. Acesso em 10 de novembro de 2015.

HENRY, T.; KOSKI, J. Short Selling Around Seasoned Equity Offerings, setembro de 2008. Disponível em: http://papers.ssrn.com/sol3/papers.cfm?abstract id=972076\&download=yes >. Acesso em 17 de outubro de 2011.

GERARD, B.; NANDA, V. Trading and Manipulation aroud Seasoned Equity Offerings. Journal of Finance. vol. 48. 1993.

KHURSHED, Arif, et al. Transparent Bookbuilding, certification and initial public offerings. Journal of Financial Markets. vol. 19. 2014. 
KIM, Kenneth A.; SHIN, Hyuan-Han. The Puzzling Increase in the Underpricing of Seasoned Equity Offerings. The Financial Review. n ${ }^{\circ} 39$, 2004.

LEE, Inmoo. et al. The costs of raising capital. Journal of Financial Research. vol. 19. 1996.

MATARESE, James. Proposed Amendments to Rule 105 Regarding Short Selling in Connection with Public Offerings. Hedge Fund Alert. Goodwin Procter. Dezembro de 2006. Disponível em:< http://www.goodwinprocter.com/ /media/Files/Publications/Newsletters/H edge\%20Fund\%20Alert/2006/Proposed Amendments to Rule 105 Regar ding_Short_Selling_in_Connection_with_Public_Offerings.pdf>. Acesso em 10 de novembro de 2015.

MARX, Daniel; WOOD, Lisa. SEC Enforcement Year in Review: Auctions and Issues from 2013. The Investment lawyer, covering legal and regulatory issues of aset management. vol. 21. No 1. Janeiro de 2014.

PINHEIRO, Douglas Beserra; CARVALHO, Antonio Gledson. A Relevância do Processo de Estabilização no Retorno de Curto Prazo dos IPOs. $2009 . \quad$ Disponível em: <http://webcache.googleusercontent.com/search?q=cache:fOxzoDEm49sJ:b ibliotecadigital.fgv.br/ocs/index.php/sbe/EBE09/paper/download/983/371+ $\& c d=1 \& h l=e n \& c t=c l n k \& g l=b r>$. Acesso em 10 de novembro de 2015.

ROCK, Kevin. Why new issues are underpriced. Journal of Financial Economics. vol. 15, 1986. 
SAITO, Richard; PEREIRA, João André C.M. Bookbuilding e Alocação Estratégica: Evidência do Mercado de Capitais Brasileiro. Evidência do Mercado Brasileiro de Ações, Revista Brasileira de Finanças, v. 4, 2006.

SAFIEDDINE, A.; WILHELM, W. An Empirical Investigation of ShortSelling Activity Prior to Seasoned Equity Offerings. The Journal of Finance, Vol. 51, nº 2, 1996.

SCHAHIN, Fernanda Kalil. Vendas a Descoberto no âmbito do Empréstimo de Ações: estudo do modelo regulatório brasileiro. In: Revista de Direito Bancário e do Mercado de Capitais: São Paulo: Malheiros, n. 49, ano 13, jul/set, 2010.

SMITH, Clifford W. Alternative methods for raising capital: Rights versus underwritten offerings. Journal of Financial Economics. ${ }^{0}$ 5. 1977.

\section{SUPERINTENDÊNCIA DE DESENVOLVIMENTO DE MARCADO.} Audiência Pública SDM $\mathrm{n}^{\mathrm{o}}$ 04/2012. Disponível em: $<$ http://www.cvm.gov.br/export/sites/cvm/audiencias_publicas/ap_sdm/ane xos/2012/sdm0412-edital.pdf> Acesso em 10 de novembro de 2015.

\section{U.S. SECURITIES AND EXCHANGE COMMISSION. National Exam} Program: Risk Alert. Setembro de 2013. Disponível em: <http://www.sec.gov/about/offices/ocie/risk-alert-091713-rule105-regm.pdf >. Acesso em 10 de novembro de 2015.

U.S. SECURITIES AND EXCHANGE COMMISSION. Press Release 2013182. Setembro de 2013. Disponível em: < http://www.sec.gov/News/PressRelease/Detail/PressRelease/137053980437 6>. Acesso em 10 de novembro de 2015. 
U.S. SECURITIES AND EXCHANGE COMMISSION. Release No 3456206. File No. S7-20-06. Disponível em: <https://www.sec.gov/rules/final/2007/34-56206.pdf> Acesso em 10 de novembro de 2015.

U.S SECURITIES AND EXCHANGE COMMISSION. Regulation M: Release No. 34-38067. 1997. Disponível em: <https://www.sec.gov/rules/final/3438067.txt>. 